Article

\title{
Atroxlysin-III, A Metalloproteinase from the Venom of the Peruvian Pit Viper Snake Bothrops atrox (Jergón) Induces Glycoprotein VI Shedding and Impairs Platelet Function
}

\author{
Luciana S. Oliveira ${ }^{1}$, Maria Inácia Estevão-Costa ${ }^{2}$, Valéria G. Alvarenga ${ }^{1}{ }^{(1)}$, \\ Dan E. Vivas-Ruiz ${ }^{3}{ }^{(0)}$, Armando Yarleque ${ }^{3}$, Augusto Martins Lima ${ }^{4}\left({ }^{\circ}\right.$, Ana Cavaco ${ }^{2}{ }^{(D)}$, \\ Johannes A. Eble ${ }^{2}$ (D) and Eladio F. Sanchez ${ }^{1, *}$ \\ 1 Research and Development Center, Ezequiel Dias Foundation, 30510-010 Belo Horizonte, MG, Brazil; \\ luciana.oliveira@funed.mg.gov.br (L.S.O.); valeria.alvarenga@funed.mg.gov.br (V.G.A.) \\ 2 Institute of Physiological Chemistry and Pathobiochemistry, University of Münster, 48149 Münster, Germany; \\ mina.estevao@gmail.com (M.I.E.-C.); acmcavaco@gmail.com (A.C.); johannes.eble@uni-muenster.de (J.A.E.) \\ 3 Laboratorio de Biología Molecular-Facultad de Ciencias Biológicas, Universidad Nacional Mayor de San Marcos, \\ Av. Venezuela Cdra 34 S/N, Ciudad Universitaria, Lima 01, Lima 14-0576, Peru; \\ dvivasr@unmsm.edu.pe (D.E.V.-R.); ayarlequec@unmsm.edu.pe (A.Y.) \\ 4 Laboratory of Hemodynamics and Cardiovascular Technology, École Polytechnique Fédérale de Lausanne, \\ 1015 Lausanne, Switzerland; augusto.martinslima@epfl.ch \\ * Correspondence: eladio.flores@funed.mg.gov.br; Tel.: + 55-31-3314-4784
}

Received: 9 August 2019; Accepted: 24 September 2019; Published: 26 September 2019

\begin{abstract}
Atroxlysin-III (Atr-III) was purified from the venom of Bothrops atrox. This 56-kDa protein bears N-linked glycoconjugates and is a P-III hemorrhagic metalloproteinase. Its cDNA-deduced amino acid sequence reveals a multidomain structure including a proprotein, a metalloproteinase, a disintegrin-like and a cysteine-rich domain. Its identity with bothropasin and jararhagin from Bothrops jararaca is $97 \%$ and $95 \%$, respectively. Its enzymatic activity is metal ion-dependent. The divalent cations, $\mathrm{Mg}^{2+}$ and $\mathrm{Ca}^{2+}$, enhance its activity, whereas excess $\mathrm{Zn}^{2+}$ inhibits it. Chemical modification of the $\mathrm{Zn}^{2+}$-complexing histidine residues within the active site by using diethylpyrocarbonate (DEPC) inactivates it. Atr-III degrades plasma fibronectin, type I-collagen, and mainly the $\alpha$-chains of fibrinogen and fibrin. The von Willebrand factor (vWF) A1-domain, which harbors the binding site for GPIb, is not hydrolyzed. Platelets interact with collagen via receptors for collagen, glycoprotein VI (GPVI), and $\alpha 2 \beta 1$ integrin. Neither the $\alpha 2 \beta 1$ integrin nor its collagen-binding A-domain is fragmented by Atr-III. In contrast, Atr-III cleaves glycoprotein VI (GPVI) into a soluble $\sim 55-\mathrm{kDa}$ fragment (sGPVI). Thereby, it inhibits aggregation of platelets which had been stimulated by convulxin, a GPVI agonist. Selectively, Atr-III targets GPVI antagonistically and thus contributes to the antithrombotic effect of envenomation by Bothrops atrox.
\end{abstract}

Keywords: snake venoms; metalloproteinase/disintegrin; extracellular matrix; atroxlysin-III; platelets; glycoprotein VI

\section{Introduction}

Bioactive snake venom compounds have evolved from convergent or divergent evolution [1-3]. Due to their high efficacy, several venom proteins/peptides, which interfere with hemostasis by affecting coagulation and/or platelet function, have been harnessed in the diagnosis and treatment of hemostatic disorders [4-7]. Snake venom metalloproteinases (SVMPs) account for more than 30\% of 
venom proteins in most Viperidae venoms and hence majorly contribute to the symptoms of viperid envenomation [8,9]. SVMPs are classified according to their domain organization into P-I to P-III classes [10-12]. Class P-I (P-I) is composed of a metalloproteinase (M) domain of about 200 amino acid residues $[13,14]$. P-II and P-III SVMPs have an additional disintegrin (-like) (D) domain and cysteine-rich (C) domain, in addition to the M domain. P-III group are further classified into sub-classes based on their different post-translational modifications, such as proteolytic processing between the $\mathrm{M}$ and D domains (P-IIIb) or dimerization (P-IIIc). The multimeric P-IV class of SVMPs (formerly P-IV), containing an additional snake C-type lectin-like proteins (snaclecs) [10-15], has meanwhile been included in the P-III class as a subclass (P-IIId) since no mRNA transcript has been found until now. The criterion for this classification was based on the presence or absence of several non-catalytic domains as evidenced via mRNA transcripts and proteins purified in the venom [11]. The P-III SVMPs exert strong hemorrhagic activities, likely because the M-domain is supported by the non-catalytic $\mathrm{D}$ and $\mathrm{C}$ domains. They harbor several substrate binding sites (exosites) in the disintegrin loop and hyper-variable region (HVR) [15,16]. Moreover, disintegrins and P-III SVMPs antagonize platelet aggregation by preventing $\alpha \mathrm{IIb} \beta \mathrm{III}$ integrin from the binding of fibrinogen and the von Willebrand factor (vWF) [17,18].

Sharing the homologous structure of their catalytic domain, SVMPs, together with members of the ADAMs (a disintegrin and metalloproteinase) protein subfamily and ADAMTS (a disintegrin and metalloproteinase with thrombospondin motif) as well as with matrix metalloproteinases (MMPs) form the M12 clan of metalloproteinases (Merop database: http://merops.sanger.ac.uk/) [10-12,16]. These proteinases degrade several essential proteins, such as plasma proteins, extracellular matrix (ECM) components, and blood coagulation factors. They also affect platelet inter alia by cleaving their adhesion receptors [14-18], among which glycoprotein (GP) GPVI and GPIb $\alpha$ of the GPIb-IX-V complex are crucial for thrombus formation at arterial shear rates [19-21]. GPVI is a collagen-binding platelet receptor that mediates platelet adhesion and aggregation at relatively low physiological shear stress while the vWF-receptor, GPIb-IX-V, elicits platelet aggregation under high shear conditions in arterioles and stenotic arteries [19,21]. Acurhagin from Deinagkistrodon (formerly Agkistrodon) acutus venom antithrombotically targets GPVI and collagen [22]. Jararhagin, from B. jararaca venom, inhibits collagen-induced platelet aggregation by non-enzymatically interfering with the collagen- $\alpha 2 \beta 1$ integrin interaction and by proteolytically cleaving the $\beta 1$ subunit on the platelet membrane $[18,23]$. Other studies indicated that the P-III SVMPs alborhagin (Trimeresurus albolabris) and crotarhagin (Crotalus horridus horridus) induced GPVI proteolysis by a mechanism that involves platelet stimulation, and activation of endogenous platelet sheddases [24].

Bothrops (lanceheads) are neotropical pit viper snakes of medical relevance, which are widely spread throughout the tropical and non-tropical regions of Central and South American countries $[8,25]$. B. atrox is responsible for approximately $83 \%$ of all recorded snake bites throughout the Amazon region and thus surpasses any other South American venomous snake [25-27]. Furthermore, the vast majority of notified snake bites $(\sim 85 \%)$ in the tropical rainforests regions of eastern Peru are due to $B$. atrox $[13,28]$. The most clinical manifestations of $B$. atrox bite are local tissue damage and/or severe systemic hemorrhages, and may vary in different regions of the Amazonian range [25-27]. These detrimental effects are induced mostly by SVMPs such as the P-I class toxin termed atroxlysin-I (Atr-I) previously characterized in our laboratory [13]. Here we report a novel P-III SVMP from B. atrox venom. This is, to our knowledge, the first report on the isolation and biochemical characterization of a high molecular mass hemorrhagic metalloproteinase from Peruvian B. atrox venom. We propose the name atroxlysin-III (Atr-III) considering, the original source (atrox-) and the proteolytic action (-lysin) of the P-III class metalloproteinase. Its complete amino acid sequence was deduced from the corresponding cDNA. Our results of its biochemical and functional properties reveal the molecular mechanism of Atr-III on platelet function, hemostasis, and thrombosis. 


\section{Results}

\subsection{Purification of Atroxlysin-III}

The progress of purification was followed by determining the proteolytic activity on dimethylcasein (DMC), fibrinolytic activity, coagulant activity on fibrinogen (Fg) and by measuring the hemorrhagic effect of each fraction in vivo. First, gel filtration on a Sephacryl S-200 column separated the crude venom into eight peaks (P1 to P8, Figure S1). Proteolytic and hemorrhagic activity were concentrated in peaks P1 and P4, representing high and low Mr proteins of $<50$ and $\sim 23 \mathrm{kDa}$. The latter contained the previously described Atr-I, a P-I class SVMP [13]. Peak P1 contained the hemorrhagic metalloproteinase of P-III class and was further separated by a DEAE Sepharose column into five peaks (A, B, C, D, and E; Figure S1). Peak C contains the hemorrhagic and proteolytic activity and showed a major band in SDS PAGE with only minor contaminants. Further purification with a Sephacryl S-200 column (Figure 1A) yielded an active proteinase with mol. mass of approximately 56 and $60 \mathrm{kDa}$ under reducing and non-reducing conditions, respectively (Figure 1, inset). MALDI-TOF-TOF revealed its mass to be 56,681.8 Da (Figure 1B). The characteristic proteolytic and hemorrhagic properties of Atr-III are presented in Table 1.

A

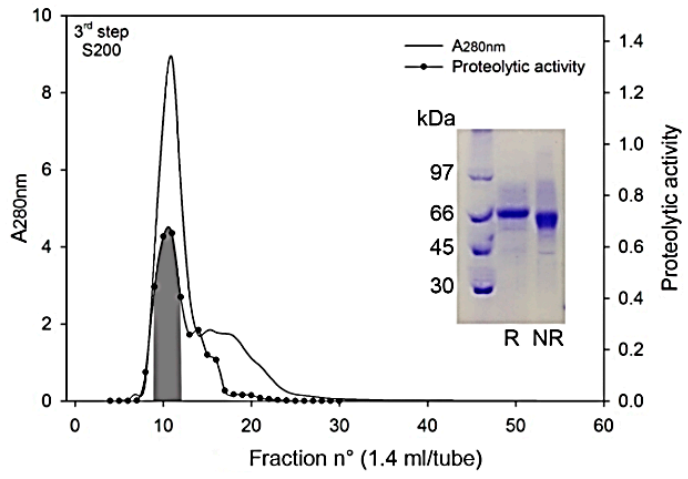

B

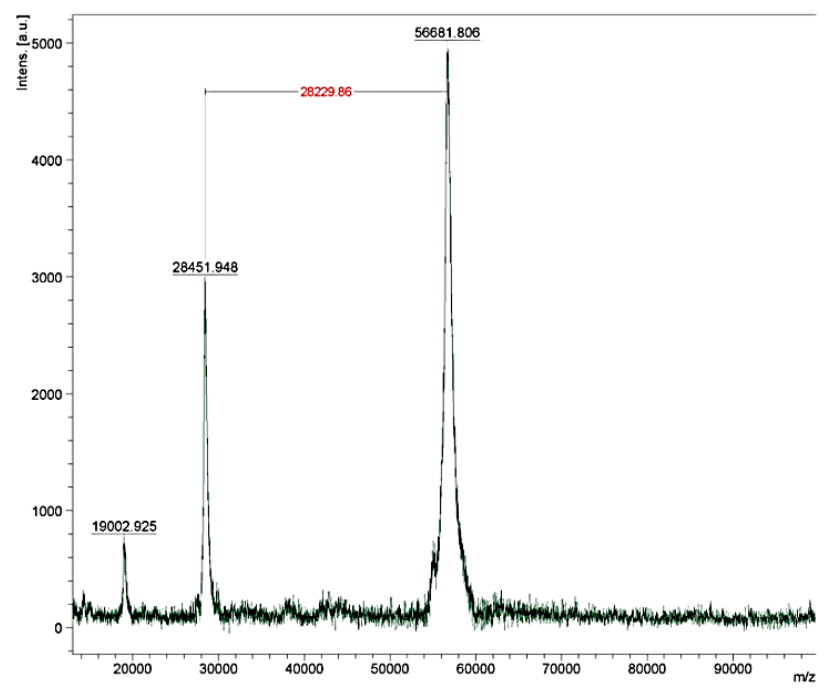

Figure 1. Purification of Atroxlysin-III from B. atrox venom (3rd step). (A) Fraction from the second step (DEAE-ion exchange column) containing hemorrhagic activity was applied to a Sephacryl 200 column. The column was equilibrated and eluted with $50 \mathrm{mM}$ Hepes buffer, $\mathrm{pH}$ 8.0, containing $0.1 \mathrm{M} \mathrm{NaCl}$, $2 \mathrm{mM} \mathrm{CaCl}_{2}$ at a flow rate of $3.4 \mathrm{~mL} / \mathrm{h}$. Active fractions containing Atr-III were pooled (area under curve highlighted in grey). The inset indicates the SDS-PAGE (12\% gel) of purified Atr-III under reduced (R) and non-reducing (NR) conditions. (B) Mass spectrometry of native Atr-III. Purified Atr-III was analyzed by MALDI TOF/TOF. The main signal (displayed in arbitrary units-a.u.) corresponded to a singly charged ion of $56,681.8$ daltons. 
Table 1. Some biological activities of Atroxlysin-III from B. atrox venom.

\begin{tabular}{|c|c|c|c|}
\hline & Proteolytic $(\mathrm{U} / \mathrm{mg})^{1}$ & ${\text { Hemorrhagic }(\mathrm{U} / \mathrm{mg})^{2}}^{2}$ & Fibrinolytic $(\mathrm{U} / \mu \mathrm{g})^{3}$ Bovine Fibrin \\
\hline Crude venom & $1.45 \pm 0.39$ & $68.9 \pm 2.26$ & $7.33 \pm 0.65$ \\
\hline Atr-III & $27.8 \pm 2.47$ & $4000 \pm 1.54$ & $8.43 \pm 0.06$ \\
\hline
\end{tabular}

\subsection{Nucleotide Sequencing of Atroxlysin-III cDNA}

The primary structure of Atr-III was deduced from the corresponding cDNA isolated from the total RNA of $B$. atrox snake venom. Using RT-PCR, $30 \mathrm{ng} / \mu \mathrm{L}$ cDNA were synthesized from $150 \mu \mathrm{L}$ of freshly milked venom from one specimen. The fully assembled cDNA sequence and deduced amino acid sequence (Figure S2) revealed that pre-pro-atroxlysin-III consists of a signal sequence, a pro-domain, a metalloproteinase domain, a disintegrin-like domain and cysteine-rich domain. The signal peptide, MIHVLLVTICLAAFPYQG, is cotranslationally cleaved from the Atr-III precursor. The pro-domain harbors the activity-regulating cysteine-switch motif, PKMCGVT. After the activating cleavage of the pro-domain, a pyroglutamate residue, similar to other P-III SVMPs, forms the N-terminus of the mature protein, which comprises 420 amino acids and consists of a metalloproteinase (M), a disintegrin-like (D) and a cysteine-rich (C)-domain. The primary structure of Atr-III shares high sequence homology with other SVMPs family members including jararhagin [29], bothropasin [30], batroxrhagin [31], MP-III B. insularis [32], Leuc-B [33] and the P-I class Atr-I [13] from the same B. atrox venom (Figure 2). The sequence identities of Atr-III precursor with bothropasin, MP-III B. insularis, jararhagin, batroxrhagin, and Leuc-B are $96.9 \%, 95.2 \%, 94.3 \%, 96.7 \%$, and $63.9 \%$, respectively (Figure 2). The $\mathrm{M}$ domain contains the typical zinc-chelating motif, HEMGHNLGIHHD from residues 144 to 155 as well as the methionine-turn motif, CIM, that is also involved in zinc-binding of the metzincin superfamily of metalloproteinases $[10,11]$ (Figure 2 ). The D-domain contains a putative integrin-interacting motif ECD in the corresponding D-domain sequence that is homologous to DCD, a putative collagen binding site, which is characteristic for many P-III SVMPs. A potential Asn-linked sugar chain glycosylation motif was found at Asn183 in the M-domain. Similarly, it is also found in the corresponding regions of the other five P-III SVMPs (bothropasin, batroxrhagin, jararhagin, MP-III $B$. insularis and Leuc-B). 


Atr-III
Bothropasin
Bathroohagin
Jararhagin
B.insularis
Leuc-B
Atr-I
Consensus
Atr-III
Bothropasin
Bathroxhagin
Jararhagin
B.insularis
Leuc-B
Atr-I
Consensus
Atr-III
Bothropasin
Bathroxhagin
Jararhagin
B.insularis
Leuc-B
Atr-I
Consensus
Atr-III
Bothropasin
Bathroxhagin
Jararhagin
B.insularis
Leuc-B
Atr-I
Consensus

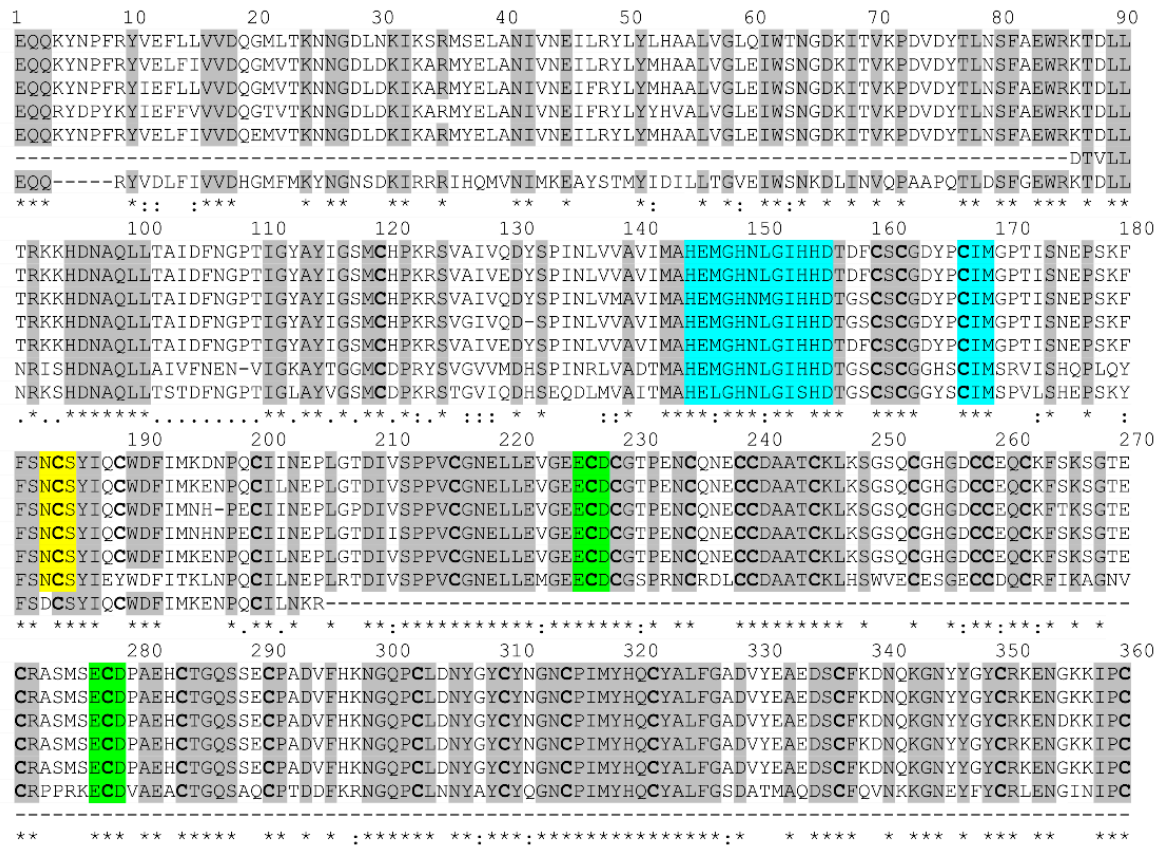

Atr-III

Bothropasin Bathroxhagin Jararhagin B.insularis

Leuc-B
Atr-I

Consensus

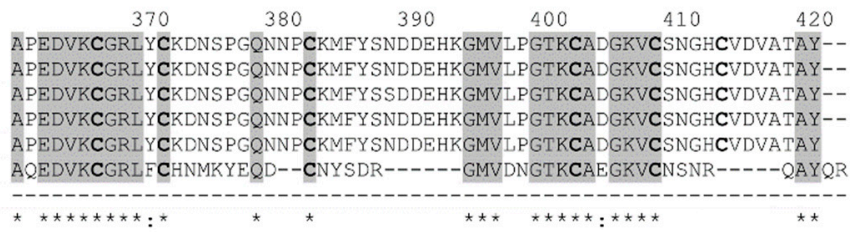

\begin{tabular}{|l|c|c|c|c|c|c|c|}
\hline Atroxlysin-III & 100.00 & 96.91 & 95.24 & 94.29 & 96.67 & 63.89 & 60.00 \\
\hline Bothropasin & 96.91 & 100.00 & 95.71 & 95.24 & 99.76 & 64.20 & 63.50 \\
\hline Bathroxhagin & 95.24 & 95.71 & 100.00 & 95.70 & 95.48 & 62.54 & 59.80 \\
\hline Jararhagin & 94.29 & 95.24 & 95.70 & 100.00 & 95.00 & 64.09 & 61.31 \\
\hline B.insularis & 96.67 & 99.76 & 95.48 & 95.00 & 100.00 & 64.20 & 63.00 \\
\hline Leuc-B & 63.89 & 64.20 & 62.54 & 64.09 & 64.20 & 100.00 & 68.07 \\
\hline Atr-I & 60.00 & 63.50 & 59.80 & 61.31 & 63.00 & 68.07 & 100.00 \\
\hline
\end{tabular}

Figure 2. Sequence alignment of Atr-III with other snake venom metalloproteinases (SVMPs) from different pit viper species. The sequence of Atr-III is aligned corresponding to those of the following venom proteins: Bothropasin from B. jararaca (AAC61986), Batroxrhagin from the Brazilian B. atrox (KR632593), Jararhagin from B. jararaca (P30431), B. insularis P-III from B. insularis (AAM09693), Leuc-B from B. leucurus (P86092) and Atr-I, a P-I SVMP from the same B. atrox venom (P85420). Amino acid numbering follows that of Atr-III. Residues are denoted if highly homologous (*) or strongly similar (:). The zinc binding motif (HEGNHLGIHHD) and the methionine 168 of the Met-turn region are invariant and are highlighted in blue. Putative N-linked glycosylation site is bold and boxed in yellow. The cysteine residues are bold and highlighted. Disintegrin-like (ECD) sequences are highlighted in green. Gaps (-) were introduced to optimize the sequence identity. a.a., amino acids. Sequences were aligned using the CLUSTAL W Program.

\subsection{Three-dimensional Model and Phylogenetic Study}

A three-dimensional model of Atr-III (Figure 3) was generated by the homology modeling software Modeller using crystal structures of B. jararaca, C. atrox and A. acutus P-III class SVMPs as templates (PDB codes: 3DSL-A, 2DW0-A and 3HDB-A, respectively). A comparison of the generated model with VAP2B [34] suggested that the disintegrin-like (D-) domain is structured into subdomains, Ds and Da. Analysis of the metal binding sites indicated that the structural model present sites for $\mathrm{Ca}^{2+}$ and 
$\mathrm{Zn}^{2+}$ binding and are in homology with the used templates. The Ds-domain protrudes from the $\mathrm{M}$-domain close to the $\mathrm{Ca}^{2+}$-binding site I but distantly from the catalytic crevice. The comparison of 22 homologous P-III class SVMPs rendered a phylogenetic tree, in which the viperid metalloproteinases are separated in three main branches (Figure 4).

A

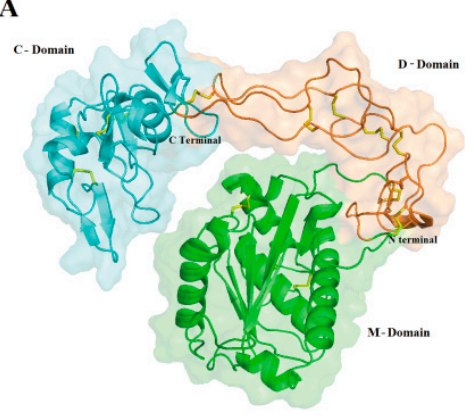

B

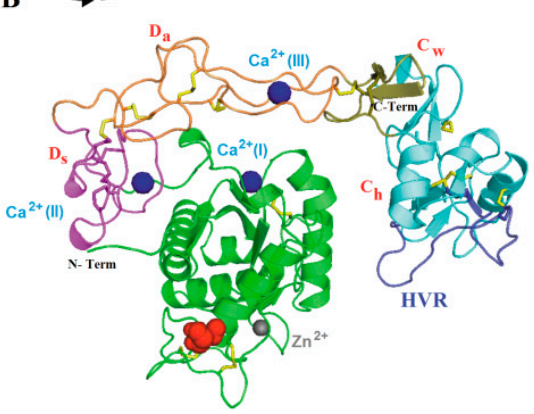

C

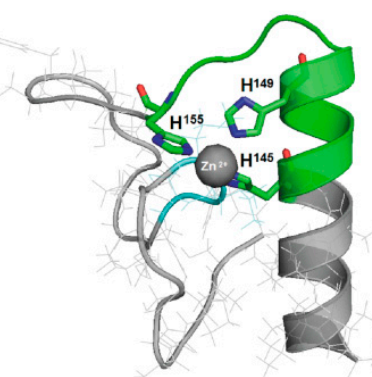

D

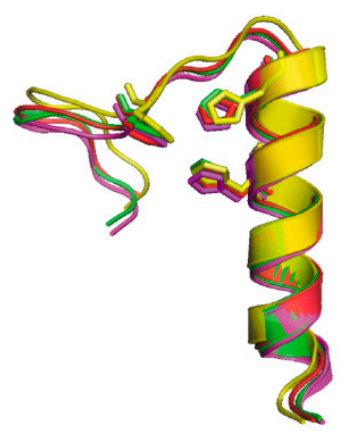

Figure 3. Theoretical Atroxlysin-III 3D model. (A) A homology model of Atr-III generated with Modeller 9.13 using crystal structures of other P-III SVMPs as templates. The metalloproteinase (M), disintegrin-like (D) and Cysteine-rich (C) domains are indicated by green, orange, and cyan colors, respectively. Elements of secondary structure $\alpha$-helices, $\beta$-structures, $\mathrm{N}$ - and $\mathrm{C}$-terminal ends are presented. Disulfide bonds are in yellow sticks. (B) Principal motifs of Atr-III according to Igarashi et al. [34]. The M-domain, $\mathrm{Ds}, \mathrm{Da}, \mathrm{Cw}$, and $\mathrm{Ch}$ segments and the hyper-variable-region (HVR) are shown in green, magenta, orange, olive, cyan, and blue, respectively. Zinc and calcium ions are represented as grey and blue spheres, respectively. N-glycosylation motif is indicated in red spheres. (C) Details of the zinc binding site of Atr-III where the positioning of the three histidine residues are shown. (D) Superposition of the zinc-binding residues of Atr-III with the P-III SVMPs are shown in sticks and labeled. B. jararaca (red), C. atrox (magenta), and A. acutus (yellow). For interpretation of the references to color in this figure legend, the reader is referred to the web version of this article. 


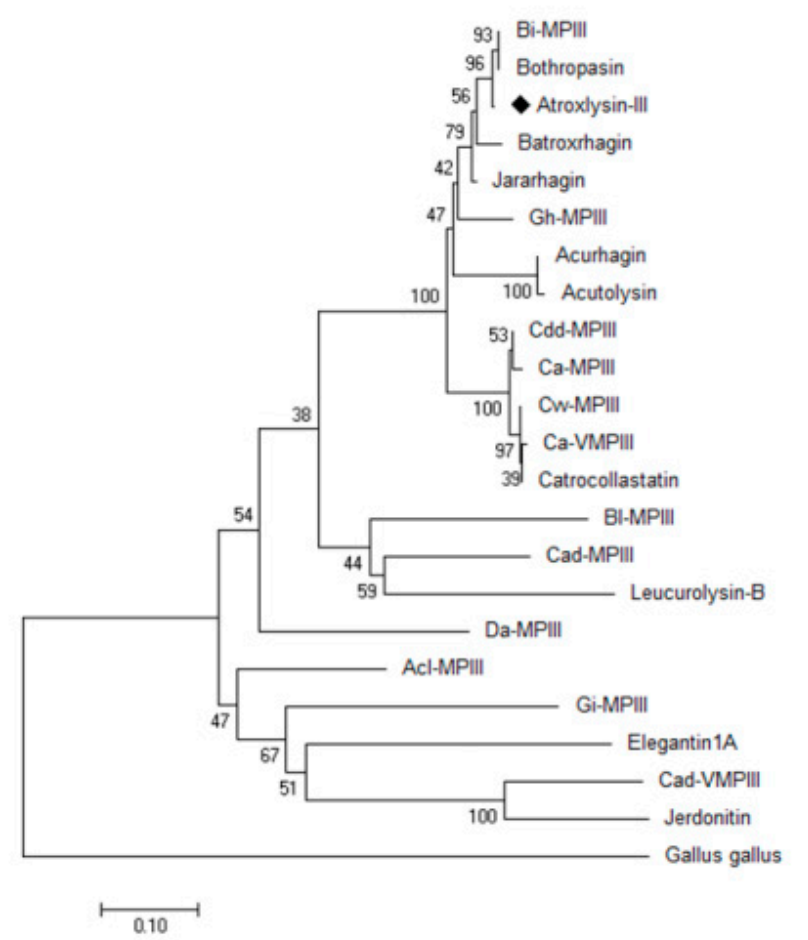

Figure 4. Phylogenetic tree of the P-III SVMPs. The amino acid sequences of 22 SVMPs were used for phylogenetic tree construction by the program Mega 5.1. Atr-III from Peruvian Bothrops atrox is marked ( ) and the others P-III class SVMPs: Bi (Bothrops insularis, AF490534); Bothropasin (Bothrops jararaca, AAC61986); Batroxrhagin (Brazilian B. atrox, ALB00542); Jararhagin (B. jararaca, CAA48323); Gh-MPIII (Gloydius halys, AAD02652); Acurhagin (Deinagkistrodon acutus, AAS57937); Acutolysin (Deinagkistrodon acutus, AAD27891); Cd MPIII (Crotalus durissus durissus, ABA42117); Ca-MPIII (Crotalus atrox, A4PBQ9); Cvv-MPIII (Crotalus viridis viridis, ACV83933); Ca-VMPIII (Crotalus atrox, ACV83931); Catrocollastatin (Crotalus atrox, AAC59672); Bl-MPIII (Bothriechis lateralis, AGY49227); Cad MPIII (Crotalus adamanteus, J3S830); leucurolysin-B (Bothrops leucurus, P86092); Da MPIII (Deinagkistrodon acutus, BAO23490); Acl-MPIII (Agkistrodon contortrix laticinctus, ACV83929); Gi-MPIII (Gloydius intermedius, AJI77146); elegantin1A (Protobothrops elegans, BAB69657); Ca-VMPIII (Crotalus adamanteus, AEJ31986); Jerdonitin (Protobothrops jerdonii, AAQ63966); and Gallus gallus ADAM9 was used as the outgroup (NP-001026567).

\subsection{Biochemical Features of Atr-III}

Digestion of DMC was employed to quantify the proteolytic activity of Atr-III Ca ${ }^{2+}(115 \%)$ and $\mathrm{Mg}^{2+}(114 \%)$ slightly increased (Figure 5A), whereas addition of $\mathrm{Zn}^{2+}$ decreased the activity of Atr-III in a concentration-depended way (Figure 5B). We chemically modified Atr-III with diethylpyrocarbonate (DEPC) which specifically reacts with the imidazole ring of histidines. DEPC-modified Atr-III failed to digest fibrinogen $(\mathrm{Fg}$ ) (Figure $5 \mathrm{C}$ ) whereas untreated enzyme completely digested the $\alpha$-chain of Fg within 15 min. Hence, Atr-III is a metalloproteinase and essentially requires complexation of a zinc-ion by histidyl residues in the active site. This explains the inhibition of Atr-III activity with a chelating agent EDTA and with the synthetic metalloproteinase inhibitors, batimastat (BAT) and marimastat (MAR). Conversely, PMSF, an active-site serine proteinase inhibitor, had no effect. Proteolysis of DMC was also blocked by the specific inhibitors MMP-inhibitor-III (I-MMP-III) and collagenase-inhibitor-I (I-Coll-I) by approximately $70 \%$ and $65 \%$, respectively (Figure 5A). In increasing concentrations, $\alpha-2$ macroglobulin $(\alpha 2 \mathrm{M})\left(5 \mathrm{~min}\right.$ at $\left.37^{\circ} \mathrm{C}\right)$ was cleaved by Atr-III into the characteristic $90 \mathrm{kDa}$ fragment, likely due to the cleavage of the Arg696-Leu697 bond (Figure 5D). In contrast to the complete inhibition of Atr-I and other P-I SVMPs with $\alpha 2 \mathrm{M}$ at an equimolar ratio [13,14], the proteolytic activity of Atr-III on DMC was not significantly inhibited by $\alpha 2 \mathrm{M}$ (not shown). These in vitro data on proteolytic activity of Atr-III were in line with the hemorrhagic effect of the enzyme in mouse model. 


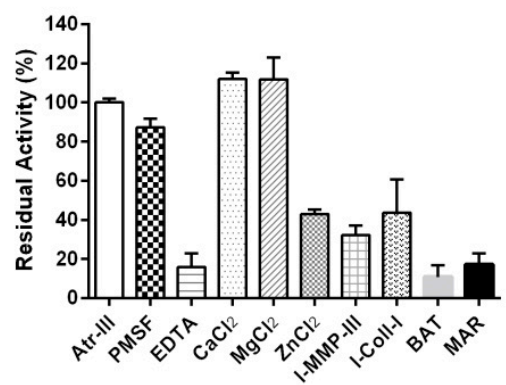

C

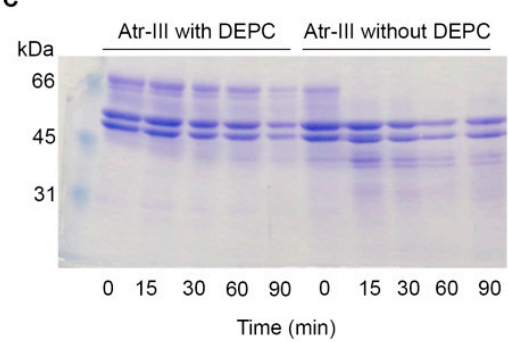

B

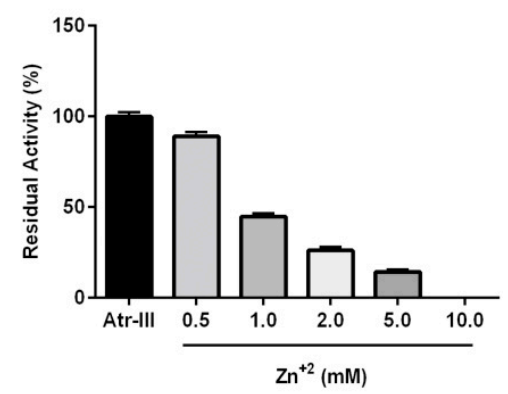

D

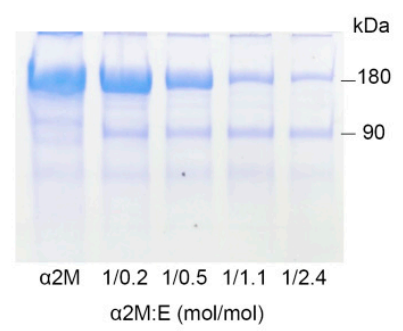

Figure 5. Biochemical properties of Atr-III. (A) Effect of several reagents on the proteolytic activity of Atr-III. The isolated Atr-III $(1 \mu \mathrm{g})$ was treated with each reagent as described in the experimental procedures. The remaining activity was measured with DMC as substrate. (B) Atr-III (1 $\mu$ g) was preincubated with $\mathrm{Zn}^{2+}$ at the indicated concentrations for $20 \mathrm{~min}, \mathrm{pH} 7.3$ at $37^{\circ} \mathrm{C}$. The remaining activity was tested with DMC. (C) Fibrinogen digestion by Atr-III with and without DEPC modification as described in the experimental procedures. (D) Atr-III $(2 \mu \mathrm{g})$ was incubated with $\alpha 2 \mathrm{M}$ as described in the experimental procedures. The products of enzyme: $\alpha 2 \mathrm{M}$ interaction were analyzed by SDS-PAGE. In $(\mathbf{A}, \mathbf{B})$, values represent the means $\pm \mathrm{SD}(n=3)$. (C,D) show representative results out of three similar experiments.

Atr-III bore N-linked glycoconjugates, a frequent property of P-III SVMPs. The presence of carbohydrate moieties on Atr-III was proven by incubating the enzyme with recombinant PNGase F. After treatment with PNGase F, Atr-III shows a $7 \mathrm{kDa}$ lower Mr in SDS-PAGE under reducing conditions as compared to untreated Atr-III (Figure 6A, lane 2). In contrast, incubation with O-glycosidase did not alter the size of the proteinase (Figure 6A, lane 3). The carbohydrate moiety of Atr-III affected its stability and functional activity, as Atr-III pretreated with PNGase F under non-denaturing conditions changed its proteolytic activity on Fg and DMC. While untreated Atr-III digested the $\alpha$-chain of Fg completely (Figure 6B, lane 1), digestion of Fg with deglycosylated enzyme showed an additional, yet minor protein band below the $\beta$-chain of Fg, suggesting that deglycosylation of Atr-III partially reduced its structural stability. In addition, DMC proteolysis with deglycosylated Atr-III under non-denaturing conditions revealed a partial loss of enzymatic activity in comparison with untreated enzyme (Figure 6C). 
A

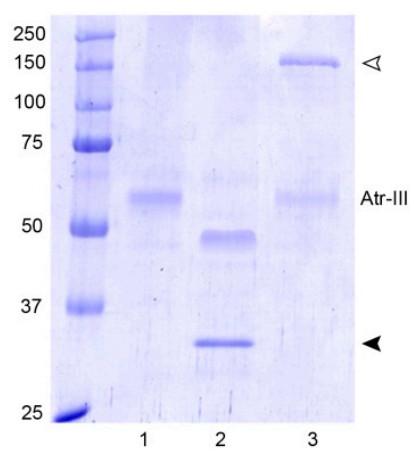

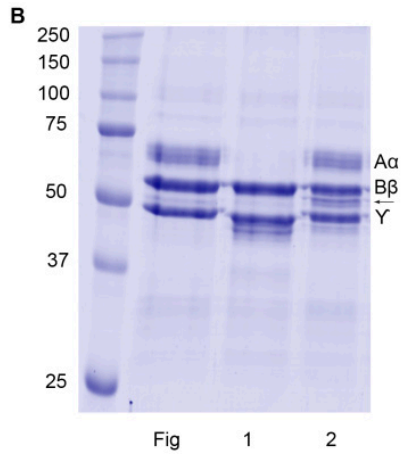

c

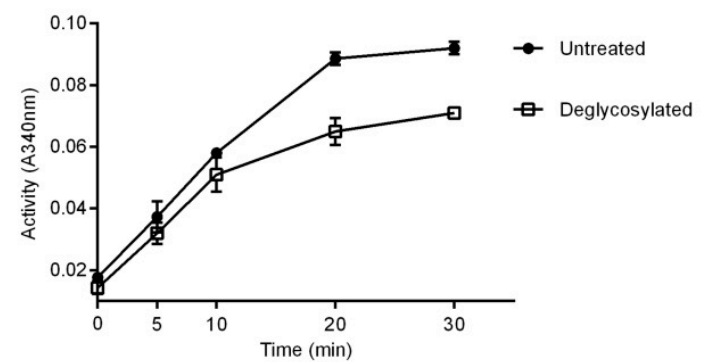

Figure 6. Deglycosylation of Atr-III. (A) SDS-PAGE (12\% gel) of Atr-III untreated (1), or after treatment with PNGase F (2) or O-glycosidase (3), a band at $\sim 35 \mathrm{kDa}$ in lane 2 is an excess of PNGase F (indicated by a black arrow head) and a band at $\sim 150 \mathrm{kDa}$ is O-glycosidase (open arrow head). (B) Undigested fibrinogen (Fg), and Fg digested with Atr-III (1) or Fg treated with N-deglycosylated Atr-III (2). Molecular mass markers are shown in the left lanes of (A,B). (C) DMC hydrolysis by Atr-III (2 $\mu \mathrm{g})$ without (-๑) or with prior treatment with PNGase F (-ם-). Results are presented as SD $(n=3)$. Note that loss of N-deglycosylation affected the venom enzyme activity.

\subsection{Effect of Atr-III on Plasma and ECM Components}

SVMPs generally have fibrino(geno)lytic activities and might degrade ECM proteins resulting in hemostatic dysfunction and hemorrhagic attack of the microvasculature integrity, respectively. Hence, proteolytic activity of Atr-III on Fg, fibrin, fibronectin (FN), type I collagen, IV and laminin-111 (LM), was analyzed. As the $\alpha$-chains of Fg or fibrin were degraded within 5 min, Atr-III was classified as an $\alpha$-fibrinogenase (Figure 7A,B). FN is degraded by Atr-III at a molar enzyme:substrate ratio of 1:100 to one major band of $\sim 58-\mathrm{kDa}$, which was also released by the hemorrhagic P-I class Atr-I [13]. Other two degradation fragments of approximately 190 and $170 \mathrm{kDa}$, respectively, were observed within 15 min on reduced SDS-PAGE (Figure 7C). Furthermore, Atr-III hydrolyzed the fibril-forming type I collagen, as its $\alpha 1 \alpha 1, \alpha 1 \alpha 2$, and partially the $\alpha 1$ and $\alpha 2$ chains were totally digested after $4 \mathrm{~h}$ and $6 \mathrm{~h}$ (Figure 7D). In contrast, Atr-III showed only minor or undetectable in vitro degradation of laminin-111 and type IV collagen, both major components of the subendothelial basement membrane (not shown). EDTA-treatment of Atr-III completely abolished its proteolytic activity on ECM proteins, Fg (Figure 7A) and fibrin. 
A

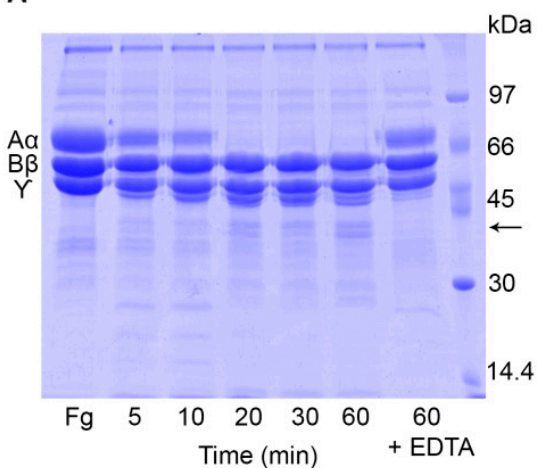

C

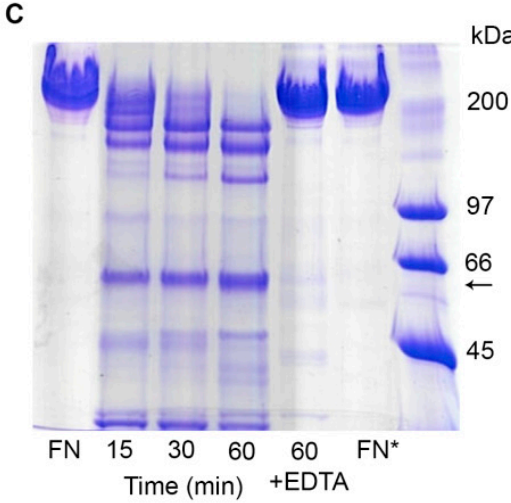

$\mathrm{E}$

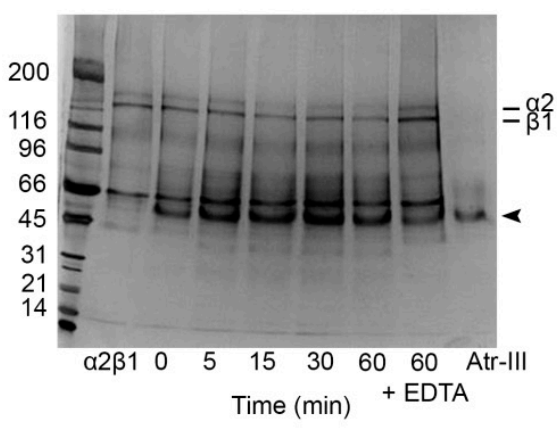

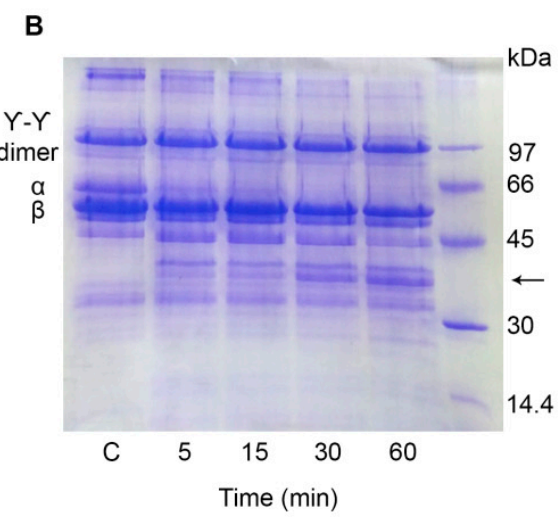

D

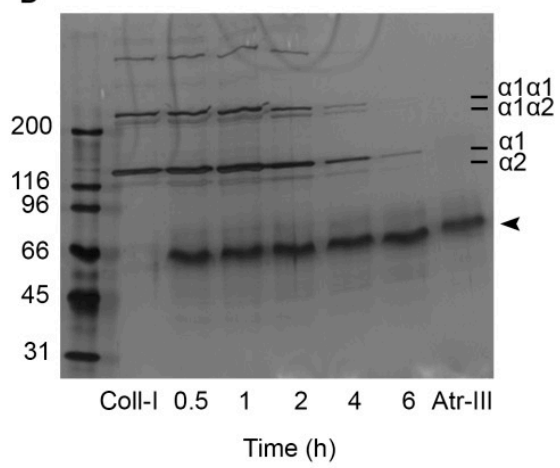

$\mathbf{F}$

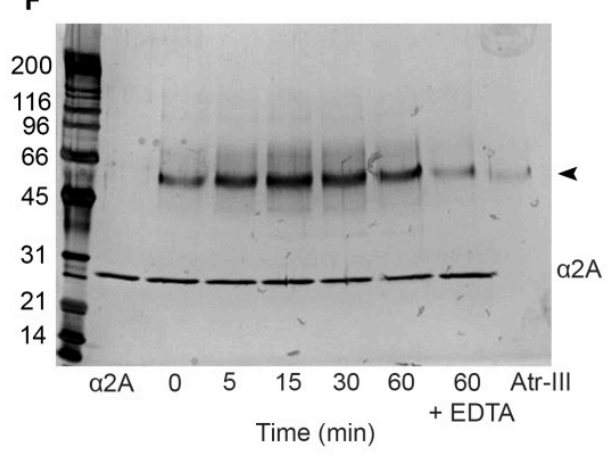

Figure 7. SDS-PAGE analysis of fibrinogen, fibrin, fibronectin, type I collagen, $\alpha 2 \beta 1$ integrin and its recombinant $\alpha 2 \mathrm{~A}$-domain ( $\mathrm{r} \alpha 2 \mathrm{~A})$ after digestion with Atr-III. Digestion reactions of $\mathrm{Fg}(\mathbf{A})$, fibrin (B), $\mathrm{FN}(\mathbf{C})$, Coll-I (D), $\alpha 2 \beta 1$ integrin (E) and its r $\alpha 2 \mathrm{~A}$ domain $(\mathbf{F})$ were carried out at molar ratio of 1:150 (enzyme/substrate) for $\mathrm{Fg}$, fibrin and $\mathrm{FN}$, and 1:50 for collagen I for the indicated intervals at $37^{\circ} \mathrm{C}$. $\alpha 2 \beta 1$ integrin or its $\mathrm{r} \alpha 2 \mathrm{~A}$ domain were incubated with $10 \mu \mathrm{g} / \mathrm{mL}$ of Atr-III for the same intervals at $37^{\circ} \mathrm{C}$. Reactions were stopped by addition of $10 \mathrm{mM}$ EDTA. Aliquots of the incubation mixtures were analyzed by SDS-PAGE under reducing conditions in 12\% gels for Fg and fibrin, 7\% for FN and $5 \%$ for collagen I and $7-15 \%$ gradient gel for $\alpha 2 \beta 1$ integrin and $\mathrm{r} \alpha 2 \mathrm{~A}$ domain. The positions of the three polypeptide chains of $\mathrm{Fg}$ control $\mathrm{A} \alpha, \mathrm{B} \beta$ and $\gamma(\mathbf{A})$ as well as fibrin control $\gamma-\gamma$ dimer, $\alpha$ and $\beta$ (B) are indicated at the left. Typical type I collagen chains (cross-linked $\alpha 1 \alpha 1, \alpha 1 \alpha 2$, chain dimers, and monomeric $\alpha 1$ and $\alpha 2$ ) are indicated at the right (D). In panels E and F, $\alpha 2 \beta 1$ or r $\alpha 2 A$-domain were incubated with $10 \mu \mathrm{g}$ of Atr-III for the indicated intervals. Reactions were stopped by addition of 10 mM EDTA and analyzed by SDS-PAGE (7-15\% gradient gel). Controls of Atr-III in (D), (E) and (F) are indicated by black arrow heads. The results shown are representative of three similar experiments.

\subsection{Atr-III also Targets Platelet Receptors}

Platelets have a critical role in hemostasis and an emerging role in physiological processes including inflammation [19-21]. So far, numerous SVMPs are known for their inhibitory effects on platelet 
aggregation induced by several agonists. The platelet surface receptor $\alpha 2 \beta 1$ integrin, which triggers collagen-induced platelet aggregation was slightly cleaved within its $\alpha 2$ subunit after 15 min (Figure 7E). EDTA-treated Atr-III completely abolished its proteolytic activity. As the collagen-binding domain of this integrin, r $\alpha 2 \mathrm{~A}$-domain, which appears as a monomer of $\sim 30-\mathrm{kDa}$ in SDS-PAGE was not cleaved by Atr-III, we concluded that Atr-III cleaved integrin $\alpha 2 \beta 1$ outside its ligand binding site (Figure 7F). Furthermore, the effect of Atr-III on GPVI, another collagen receptor of platelets, on platelet aggregation was examined by stimulation with GPVI agonists, such as convulxin (CVX) and collagen was tested by aggregometry. If platelets were pretreated for 3 min with Atr-III, the enzyme dose-dependently inhibited aggregation induced by CVX (Figure 8A and Figure S3) or collagen (Figure 8B and Figure S3) with half-maximal inhibition concentration $\left(\mathrm{IC}_{50}\right.$ ) values of 0.33 and $0.20 \mu \mathrm{M}$, respectively. Conversely, Atr-III blocked vWF-ristocetin (Ris)-induced platelet aggregation very weakly (Figure 8C and Figure S3). Moreover, platelet aggregation induced by thrombin, which activates platelets in a different way, was only slightly delayed but not inhibited (not shown). These results suggest that signal transduction within platelets via other receptors is not affected by Atr-III.

A
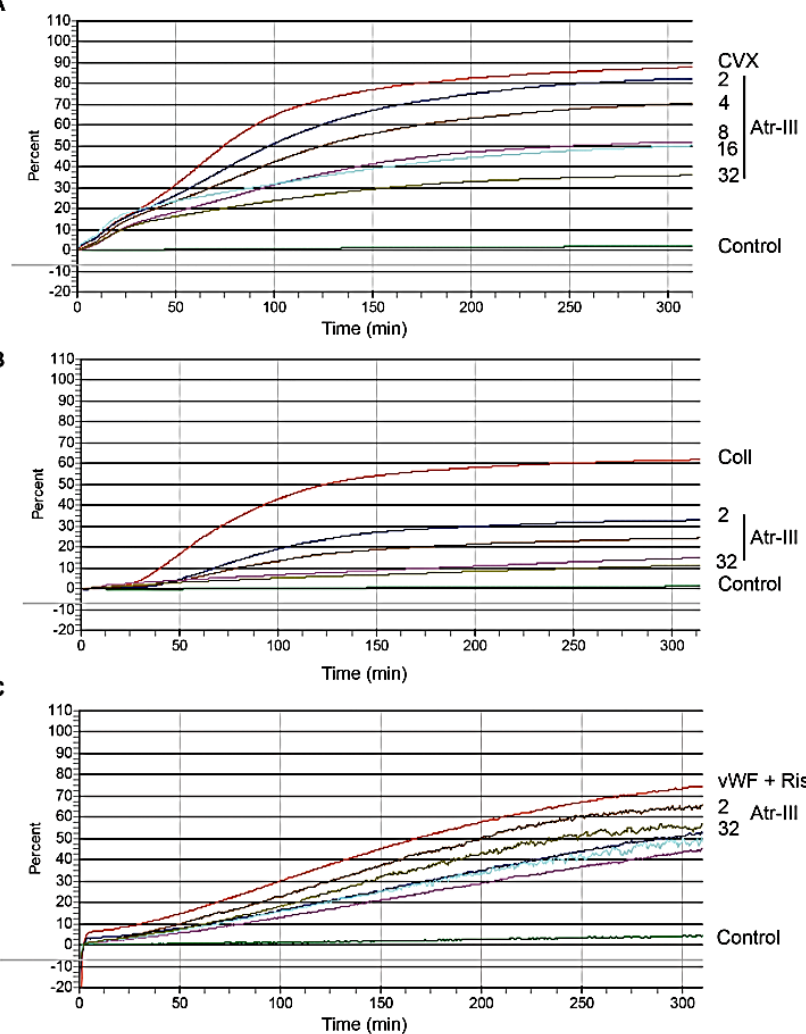

Figure 8. Atr-III inhibits aggregation of platelet stimulated with convulxin (CVX) (A) or collagen (B) in a concentration-dependent manner. However, it shows little effect on vWF + Ristocetin (Ris) induced aggregation $(\mathbf{C})$. Washed human platelets $\left(225 \mu \mathrm{L}, 2.5 \times 10^{5} / \mu \mathrm{L}\right)$ were pre-incubated with different concentrations of Atr-III ( 2 to $32 \mu \mathrm{g} / \mathrm{mL}$ ) for $3 \mathrm{~min}$ and stirred (600 rpm) at $37{ }^{\circ} \mathrm{C}$, and then different platelets agonists were added (CVX, $6 \mu \mathrm{g} / \mathrm{mL})$, collagen-I $(10 \mu \mathrm{g} / \mathrm{mL})$ or vWF $(5 \mu \mathrm{g} / \mathrm{mL})+$ Ris $(0.5 \mathrm{mg} / \mathrm{mL})$, and platelet aggregation was recorded aggregometrically. The control response is shown by the upper tracing for each agonist. One of four similar experiments for each agonist is presented with platelets from different donors.

In order to investigate if the venom enzyme cleaves rvWF A1-domain which appears as a band of 35-kDa (Figure 9A) and contains the binding site for GPIb, rvWF A1-domain was incubated with Atr-III and assayed for proteolysis by SDS-PAGE. As showed (Figure 9A) the rvWF A1-domain was resistant to proteolysis by Atr-III. Furthermore, to analyze the proteolytic susceptibility of the vWF 
receptor, the GPIb-IX-V complex was challenged by Atr-III treatment of platelets at $37^{\circ} \mathrm{C}$, subjected to SDS-PAGE under reducing conditions and analyzed by immunoblotting with an anti-CD42/GPIb $\alpha$ antibody. Under our experimental conditions, GPIb $\alpha(\sim 130-\mathrm{kDa}$, named glycocalicin) was not affected by Atr-III (Figure 9B). In addition, to investigate the mechanisms for metalloproteinase-mediated ectodomain shedding of the platelet receptor GPVI on human platelets, we used anti-GPVI antibody. Atr-III induced shedding of GPVI from the platelet surface (Figure 9C). On an immunoblot of pelleted platelets developed with an anti-GPVI antibody, a band of approximately $62-\mathrm{kDa}$ indicated the appearance of intact GPVI on the platelet surface (Figure 9C, upper panel), whereas the shedded ectodomain of GPVI at $~ 55-\mathrm{kDa}$, termed soluble GPVI (sGPVI), was detected in the supernatant of platelets treated with Atr-III for 5 min (Figure 9C, lower panel). This sGPVI fragment was also detected in response to NEM (N-ethylmaleimide). NEM, which irreversibly reacts with a cysteinyl group within the prodomain of ADAMs, amongst them ADAM10/ADAM17, and thus activates these membrane-anchored sheddases on platelets activation. (Figure 9D). To further specify the role of ADAM10, we pretreated platelets with the specific inhibitor to ADAM10, GI254023X, before adding Atr-III. Whereas the inhibitor GI254023X alone did not affect GPVI shedding the $~ 55-\mathrm{kDa}$ fragment of shedded GPVI ectodomain (sGPVI) appeared in the supernatant of Atr-III-pretreated platelets despite the presence of GI254023X. Therefore, these data suggest that Atr-III induces GPVI shedding independently of ADAM10.

A

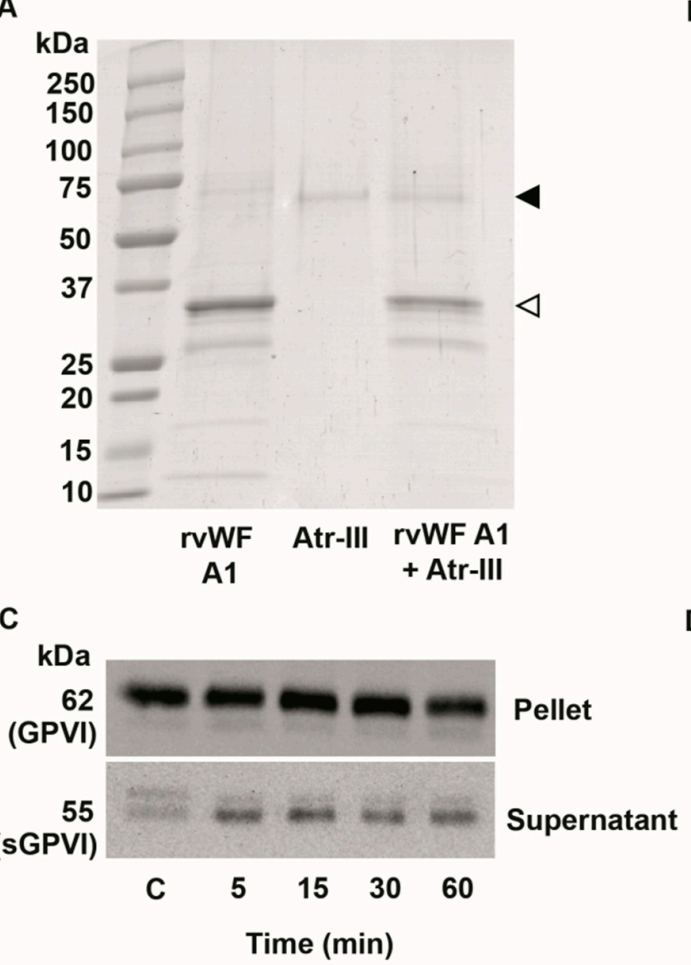

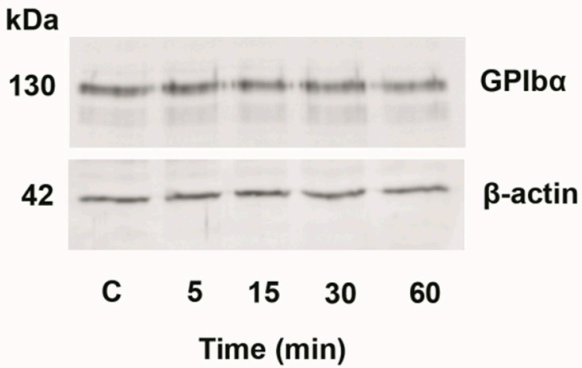

D

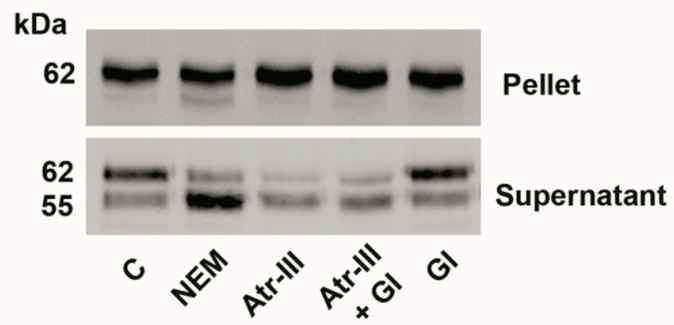

Figure 9. Atr-III does not cleave either the recombinant A1 domain of vWF (rvWF-A1) (A) nor GPIb $\alpha$ (B). (A) $5 \mu \mathrm{g}$ Atr-III was incubated with rvWF-A1 (5 $\mu \mathrm{g})$ as described in the experimental methods at $37^{\circ} \mathrm{C}$. The proteolysis of rvWF-A1 (indicated by an open arrowhead) was analyzed by SDS-PAGE (5-15\%). The black arrow head indicates Atr-III. (B) Washed platelets were incubated with Atr-III (10 $\mu \mathrm{g})$ at $37^{\circ} \mathrm{C}$ at several intervals and the reaction was stopped by addition of SDS loading sample buffer. The platelet lysate was blotted with anti-CD42/GPIb or $\beta$-actin as endogenous control. (C) Platelet pellets or supernatants of washed platelets treated with Atr-III $(10 \mu \mathrm{g})$ at $37^{\circ} \mathrm{C}$ at several intervals or (D) NEM $(10 \mathrm{mM})$, Atr-III $(10 \mu \mathrm{g})$, Atr-III $(10 \mu \mathrm{g})$ plus GI254023X (100 nM) and GI254023X (100 nM) alone were blotted with anti-GPVI antibodies. The position of GPVI (62 kDa) and the soluble $\sim 55 \mathrm{kDa}$ GPVI fragment are shown. $\mathrm{C}=$ platelet control. 
Moreover, Atr-III inhibited platelet interaction also to immobilized collagen-I, not only when added simultaneously with the platelets to the collagen-I but also when added $2 \mathrm{~h}$ after the seeded platelets had already adhered (Figure 10). In the first case, when Atr-III was added simultaneously with platelets the adhesion signal of platelets to collagen decreased throughout the entire observation period, likely due to degradation of the signaling collagen receptors. In the second case, when Atr-III was added to collagen-adherent platelets, the impedance value dropped drastically upon addition of Atr-III, indicating that Atr-III also acted on platelets after they had undergone the collagen-induced signaling and activation. This suggested that collagen receptors that mechanically anchored platelets to the collagen were degraded by Atr-III, resulting in detachment of already attached platelets and thrombi.

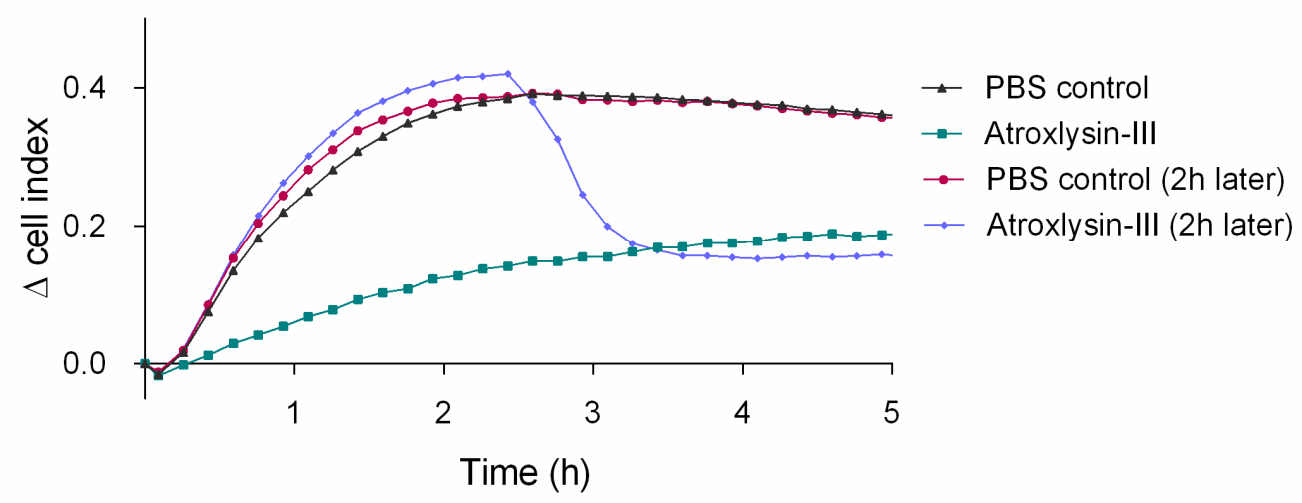

Figure 10. Platelet attachment to collagen-I-coated surface with concomitant and delayed $(2 \mathrm{~h})$ addition of Atr-III. The adhesion of platelets to collagen I was monitored by real-time impedance measurement in the xCELLigence system, on E-plates coated with $5 \mu \mathrm{g} / \mathrm{mL}$ of collagen I. Platelets treated with $32 \mu \mathrm{g} / \mathrm{mL}$ of Atr-III show a decreased adhesion, in both treatment regimens, at time 0 and $2 \mathrm{~h}$ after. The impedance values are corrected for the background values to obtain the real-time $\Delta$ cell index values. This data is representative of three independent experiments performed in duplicates.

\section{Discussion}

Fibrino(geno)lytic metalloproteinases target critical biological systems such as blood coagulation, platelet function, and hemostasis. Anticoagulant SVMPs dissolve fibrin clots and avoid clot formation, thereby inducing severe bleeding and enhancing the toxic effects of hemorrhagic metalloproteinases. In this study, we purified and characterized a novel SVMP, Atr-III from the venom of the Peruvian pit viper snake B. atrox. The mature protein has a mass of around $56-\mathrm{kDa}$, comprises 420 amino acid residues and is structured into a M-domain of 200 residues, a D-domain of 101 residues, and a C-domain of 112 residues. The proprotein of pro-Atr-III has the consensus sequence PKMCGV that implies a Cys-switch mechanism for proteolytic activation of the SVMP upon maturation of SVMPs. Atr-III is a monomeric glycoprotein. Approx. 7\% of its mol. mass is attributed to Asn-linked carboconjugates. Moreover, high Mr SVMPs which have larger carbohydrate moieties are usually more hemorrhagic [11]. In line with this, Atr-III causes hemorrhages. However, the molecular basis of how glycoconjugates affect the biochemical properties of P-III SVMPs is still unclear. They may stabilize the protein folding and, additionally, may influence binding and cleavage of substrate, as the N-linked glycoconjugate is located at Asn183 close to the Met-turn (Figure 3B), whose intrinsic flexibility has been proposed to be one of the critical decisive factors for SVMPs to cause hemorrhage [35]. Interestingly, the hemorrhagic P-I SVMP Atr-I has a non-glycosylable Asn residue at the homologous site of Asn183 of Atr-III.

The three-dimensional model of Atr-III was derived based on the VP2B structure of catrocolastatin (Figure 3A,B). More than 200 structures of metalloproteinases that have been deposited with the Protein Data Bank have revealed their common tertiary structure and active-site environment. However, each subfamily has distinct structural features. Similar to VP2B [34], Atr-III contains three $\mathrm{Ca}^{2+}$-binding sites, two of them $\left(\mathrm{Ca}^{2+}\right.$-binding sites II and III)-within the D-domain located at "shoulder" (Ds) and "arm" (Da) segments, and another $\mathrm{Ca}^{2+}$-binding site opposite to the catalytic zinc 
atom and close to the C-terminus of the $\mathrm{M}$-domain $\left(\mathrm{Ca}^{2+}\right.$-binding site $\left.\mathrm{I}\right)$ (Figure 3B). The C-domain is subdivided into "wrist" (Cw) and "hand" (Ch) segments (Figure 3B). Calcium ions likely stabilize the Atr-III structure, as proposed for other SVMPs/ADAMs and MMPs with collagenase activity. These proteinases are key participants in many, diverse immune and inflammation processes as well as in the remodeling of ECM [11,12]. Our sequence alignment of SVMPs (Figure 2) highlights that the number and spacing of cysteinyl residues are strictly conserved in the structure of SVMPS/ADAMs metalloproteinase family. Atr-III bears a disintegrin-like domain as the D and C domain are disulfide linked. The connecting cysteine within the disintegrin loop of Atr-III (SECD) is located in the generic XXCD motif of other SVMPs containing a disintegrin-like domain.

Atr-III is a member of the high Mr metalloproteinase family, consistent with the effects of $\mathrm{Ca}^{2+}$, $\mathrm{Mg}^{2+}$ and EDTA on its proteolytic activity [22,33,36-38]. Inhibition of proteolytic activity of Atr-III by adding $\mathrm{Zn}^{2+}$ may be explained by the hypothesis that Atr-III might have other $\mathrm{Zn}^{2+}$-binding sites with different binding affinity. The latter may be occupied by $\mathrm{Zn}^{2+}$ ions at high concentration, resulting in a conformational change and consequently loss of enzymatic function, as have been suggested for a P-III SVMP acurhagin from A. acutus venom [36]. To prove this hypothesis Atr-III was treated with different concentrations of $\mathrm{Zn}^{2+}$ before measured its proteolytic activity at $\mathrm{pH}$ 7.3. Regarding this point we observed a dose-dependent inhibition of DMC proteolysis by Atr-III with a complete blocked

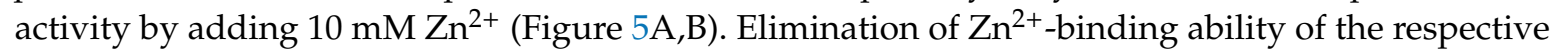
histidines residues proves that the biological functions of Atr-III is mainly, but not necessarily, based on its proteolytic activity. The most detrimental among the pathophysiological effects of P-III SVMPs is the strong hemorrhagic activity, which disrupts either the process of hemostasis and or the interactions of cellular receptors and their ligands. Among the substrates of Atr-III are not only coagulation proteins, such as fibrin(ogen) but also ECM proteins of the vascular walls and adhesion receptors of platelets. It is particularly noteworthy that envenoming by Bothrops snakes are characterized by drastic hemostatic disturbances and inflammatory reactions with local tissue damage irradiating from the site of the bite [39]. Several studies demonstrate the ability of hemorrhagic metalloproteinases to degrade proteins of the basement membrane (BM) and other extracellular macromolecules using in vitro and in vivo strategies [38]. The broad substrate spectrum of Atr-III and other P-III SVMPs may be mediated not only by substrate recognition via the catalytic $M$ domain but also by the non-enzymatic interaction of substrate with the non-proteinase domains (DC) in P-III SVMPs. The latter contain exosites that direct the interaction of these P-III SVMPs to specific ECM targets, especially in microvessels or in the plasma membrane of cells and platelets [37]. Furthermore, the presence of these domains may prevent the inhibition of these large metalloproteinases by endogenous inhibitors mainly by $\alpha 2 \mathrm{M}$ in plasma or body fluids $[34,38]$. Owing to their multiple functions, the P-III SVMPs containing MDC domains found mostly in viper venoms species may serve as potential tools to better understand how these enzymes affect the mechanisms underlying thrombosis, hemostasis, and inflammatory reactions [23].

Our real-time adhesion results revealed that Atr-III impairs the interaction of platelets with collagen-I. The prerequisite for platelet adhesion to ECM proteins is platelet activation triggered by the collagen signaling receptors such as GPVI [24]. This leads to platelet spreading and a robust anchorage predominantly via $\alpha 2 \beta 1$ integrin. Therefore, several agents were designed to target platelet adhesion specifically, e.g., monoclonal antibodies directed against the GPVI receptor, and to interfere or temper the GPVI-collagen interaction [40]. Addition of Atr-III to platelets simultaneously while they are getting in contact with collagen-I affected and reduced signaling and platelet activation via GPVI. Distinctly, when adding Atr-III to the already adherent platelets, the detachment of adherent platelets and thrombi suggested that other collagen receptors of platelets may also be affected by Atr-III. Such a candidate target of Atr-III could be the anchoring receptor $\alpha 2 \beta 1$ integrin. We ruled out this hypothesis (data not shown) as the biochemical digestion assay revealed that only the integrin $\alpha 2$-subunit showed a slight, if not quantitatively negligible cleavage while the integrin $\beta 1$-subunit seemed to be proteolytically robust against Atr-III. Moreover, the collagen-binding A-domain of $\alpha 2 \beta 1$ integrin was entirely resistant to Atr-III. The platelet collagen receptor GPVI contributes far 
more to the inhibitory effect of Atr-III on convulxin- and collagen-induced platelet aggregation than interaction with integrin $\alpha 2 \beta 1$. In this respect, the antiplatelet properties of Atr-III are similar to a homologous SVMP AAVI identified in Formosan Agkistrodon acutus venom that also function as GPVI antagonist [40]. It is of interest in this context that abnormally low levels of GPVI, caused by disease or deficiency, enhances its ADAM10-mediated shedding. This parameter together with elevated plasma sGPVI could be associated with an increase of risk of bleeding as observed in victims of viperid envenomation $[41,42]$.

\section{Materials and Methods}

The venom was pooled from adults B. atrox specimens of both sexes, which had been captured in the rain forest of Alto Marañon (Peru) and kept in captivity in the serpentarium of the Natural History Museum, Universidad Nacional Mayor de San Marcos (UNMSM, Lima-Peru). Collagen type I (C9791), collagen type IV (C7521), laminin-111 from fibroblasts (L4544), fibronectin (F2006), marimastat (M2699), batimastat (SML0041), N-Ethylmaleimide (E3876), PMSF (78830), ADP (A2754), thrombin (112374), bovine (F8630), and human (F4129) fibrinogen essentially plasminogen free were obtained from Sigma Chemical (St. Louis, MO, USA). Type I collagen (5368), von Willebrand factor (vWF, 681300), ristocetin (001226) were from Helena Laboratories, Beaumont, TX, USA. N-glycosidase F (PNGase F-P0704S) and O-glycosidase (P0733S) were from New England Biolabs (Ipswich, MA, USA. MMP-III inhibitor (444264), Collagenase I inhibitor (234140), $\alpha 2-M a c r o g l o b u l i n$ from human plasma (441251) were obtained from Calbiochem (San Diego, CA, USA). All other chemicals were of analytical reagent grade. All in vivo experiments were in accordance with the guidelines of the Brazilian College for Animal Experimentation and approved by the local Ethics Committee (Protocol number CEUA/Funed: 077/2015).

\subsection{Purification of Atroxlysin III}

Atr-III was purified by a three-step purification procedure. B. atrox venom $(1.9 \mathrm{~g})$, dissolved in $12 \mathrm{~mL}$ gel filtration buffer ( $50 \mathrm{mM}$ ammonium acetate, $\mathrm{pH} 7.4,0.3 \mathrm{M} \mathrm{NaCl}$ ), was centrifuged at $6000 \times g$ and the supernatant (1.7 g protein) was separated on Sephacryl S-200 resin packed in a tandem of two $(2.5 \times 100 \mathrm{~cm}$ each $)$ columns in the same buffer. The fractions containing proteolytic and hemorrhagic activities were pooled, dialyzed against a $1 \mathrm{mM} \mathrm{CaCl}_{2}$ solution in water containing and lyophilized. Thereafter, $272 \mathrm{mg}$ of lyophilisate was dissolved in $2 \mathrm{~mL} 50 \mathrm{mM}$ Hepes buffer, pH 8.0 containing $2 \mathrm{mM} \mathrm{CaCl}_{2}$ and purified on a DEAE-Sepharose CL-6B $(1.6 \times 17.5 \mathrm{~cm})$ column with a linear salt gradient from $0-0.3 \mathrm{M} \mathrm{NaCl}$ at a flow rate of $13 \mathrm{~mL} / \mathrm{h}$. Proteolytically active and hemorrhagic fractions (35 mg) were pooled and separated by size exclusion on a Sephacryl S-200 $(1.0 \times 40 \mathrm{~cm})$ column with $50 \mathrm{mM}$ Hepes buffer, $\mathrm{pH} 8.0$, containing $0.1 \mathrm{M} \mathrm{NaCl}$ and $2 \mathrm{mM} \mathrm{CaCl}_{2}$. Active metalloproteinase fractions containing atroxlysin-III (Atr-III) were pooled, dialyzed against distilled water and lyophilized.

\subsection{MALDI-TOF Mass Spectrometry}

MALDI-TOF-TOF spectra of Atr-III were recorded and analyzed using a Bruker Autoflex III Smartbean instrument (Billerica, MA, USA) in a linear positive mode controlled by the proprietary COMPASSTM 1.2 software package. The Nd-YAG-laser power (355 nm) was manually adjusted for optimal signal appearance. A freeze-dried $0.5 \mu \mathrm{L}$ solution of salt- and detergent free protein in $30 \%$ $\mathrm{ACN}$ in $0.1 \%$ TFA was spotted on the ground steel target plate, mixed with $0.5 \mu \mathrm{L} 10 \mathrm{mg} / \mathrm{mL}$ sinapinic acid in 50\% ACN, $0.1 \%$ TFA and left to dry at room temperature (RT), next to standard protein mixtures for calibration.

\subsection{Glycosylation Studies}

The carbohydrate content of Atr-III was confirmed with PNGase F and O-glycosidase according to the manufacturer's instructions. To determine N-linked sugars, $10 \mu \mathrm{g}$ of Atr-III were added to denaturing buffer, boiled for $10 \mathrm{~min}$, and subsequently treated with glyco buffer, NP 40 (1\%) and 
2 units of recombinant PNGase $\mathrm{F}$ or $\mathrm{O}$-glycosidase for $1 \mathrm{~h}$ at $37^{\circ} \mathrm{C}$. The reaction was terminated by boiling for $5 \mathrm{~min}$. After addition of PAGE loading buffer, the reaction mixture, along with untreated control and deglycosylated enzyme, were analyzed by SDS-PAGE. To maintain the activity of Atr-III, the enzyme was also deglycosylated with PNGase $\mathrm{F}$ for $1 \mathrm{~h}$ at $37^{\circ} \mathrm{C}$ in the absence of reducing and denaturing agents [43].

\subsection{Enzymatic Features of Atr-III}

Proteolytic activity of Atr-III was assessed with the substrate DMC [44]. To test the effects of cations, Atr-III $(1 \mu \mathrm{g})$ was pretreated with $\mathrm{CaCl}_{2}, \mathrm{MgCl}_{2}$ and $\mathrm{ZnCl}_{2}(1 \mathrm{mM}$ each $)$ in $25 \mathrm{mM}$ Hepes buffer, $\mathrm{pH} 7.4$ for $30 \mathrm{~min}$ at $37^{\circ} \mathrm{C}$ before enzymatic activity was quantified by DMC digestion. DMC proteolysis of Atr-III $(1 \mu \mathrm{g})$ in $250 \mu \mathrm{L}$ of $25 \mathrm{mM}$ Hepes buffer, $\mathrm{pH} 7.4$ for $5 \mathrm{~min}$ at $37^{\circ} \mathrm{C}$ was also measured in the presence of several proteinase inhibitors: EDTA, PMSF (1 mM each), I-Coll-I, I-MMP-III (ratio of 1:50 each), synthetic MMP inhibitors: BAT and MAR $(0.5 \mu \mathrm{M}$ each), as well as the main plasma inhibitor $\alpha 2-\mathrm{M}(7.5-60 \mu \mathrm{g}$; molar enzyme:inhibitor ratios: 0.2-2.4).

\subsection{Modification of Histidine Residues in Atr-III}

The essential histidine residues of Atr-III were chemically modified to prevent Atr-III from complexing $\mathrm{Zn}^{2+}$. Thereby, the enzyme is persistently inactivated even after restoration with $\mathrm{Zn}^{2+}$. Modification of histidine with DEPC was carried out according to [45]. To this end, $20 \mu \mathrm{L}$ Atr-III $(1 \mathrm{mg} / \mathrm{mL})$ in $80 \mu \mathrm{L}$ PBS $\left(0.01 \mathrm{M} \mathrm{NaH}_{2} \mathrm{PO}_{4}, 0.15 \mathrm{M} \mathrm{NaCl}, \mathrm{pH}\right.$ 6.5) containing $0.4 \mu \mathrm{L}$ of $0.5 \mathrm{mM}$ EDTA was mixed with $4 \mu \mathrm{L}$ of $130 \mathrm{mM}$ DEPC/waterfree acetonitrile (ACN) $(5 \mathrm{mM}$ final concentration DEPC and $3.8 \% \mathrm{ACN}$ ), incubated at $15^{\circ} \mathrm{C}$ for $1 \mathrm{~h}$ in thermomixer ( $\left.300 \mathrm{rpm}\right)$, followed by four dialysis rounds in micro dialysis tubes against PBS, pH 7.4 for 30 min each. Proteolytic activities of treated and untreated Atr-III (4 $\mu$ g each) were tested with $40 \mu \mathrm{g} \mathrm{Fg}(1.3 \mathrm{mg} / \mathrm{mL})$ in PBS, pH 7.4, containing $2 \mathrm{mM} \mathrm{CaCl}_{2}(2 \mu \mathrm{L})$ and $5 \mathrm{mM} \mathrm{Zn}$-acetate $(5 \mu \mathrm{L})$ to final volume of $100 \mu \mathrm{L}$. Samples were drawn after certain time intervals and the digestion was stopped by immediately adding $1 \mu \mathrm{L}$ of EDTA $(12 \mathrm{mM})$ and cooling on ice. TCA precipitated and acetone-washed samples were separated by SDS-PAGE (5-10\% gradient) under reducing conditions and the gel stained with Coomassie.

\subsection{Degradation of Plasma and ECM Proteins by Atr-III}

Proteolytic activity of Atr-III was also investigated on human Fg, fibrin, and fibronectin (FN). To this end, $\mathrm{Fg}$ was dissolved at a final concentration of $2.5 \mathrm{mg} / \mathrm{mL}$ in $25 \mathrm{mM}$ Tris- $\mathrm{HCl}, \mathrm{pH} 7.4$ containing $154 \mathrm{mM} \mathrm{NaCl}$. Atr-III ( $2 \mu \mathrm{g})$ was added to $100 \mu \mathrm{L}$ of Fg solution at a molar enzyme:substrate-ratio of $1: 150$ and the reaction was incubated at $37^{\circ} \mathrm{C}$. At time intervals $(5,15,30$, and $60 \mathrm{~min})$, reactions were stopped by added $40 \mu \mathrm{L}$ of denaturing solution (10 M urea, $4 \% \beta$-mercaptoethanol, $4 \%$ SDS), and analyzed by SDS-PAGE (12\% gel). The fibrinolytic activity was tested using the fibrin plate method [44]. The fibrin gels were produced by adding $2 \mathrm{NIH} \mathrm{U/mL} \mathrm{of} \mathrm{human} \mathrm{thrombin} \mathrm{(Sigma)} \mathrm{to}$ bovine $\mathrm{Fg}$ solution $(2.5 \mathrm{mg} / \mathrm{mL})$ in Tris- $\mathrm{HCl}$ buffered saline, $\mathrm{pH}$ 7.4, containing $154 \mathrm{mM} \mathrm{NaCl}$ and by incubating $2 \mathrm{~h}$ at RT. Different amounts of Atr-III in a $10 \mu \mathrm{L}$ volume were then added and incubated for $15 \mathrm{~h}$ at $37^{\circ} \mathrm{C}$. The areas of lysis were measured by flooding the plate with $10 \%$ TCA solution. Protein-chemically, degradation of fibrin and other Atr-III substrates was analyzed by SDS-PAGE $(12 \%$ gel) at different time points of digestion. Other substrates of Atr-III were plasma FN, and the ECM proteins laminin-111 (LM), type I and IV collagens at an enzyme:substrate-ratio of 1:100 (FN) and 1:50, respectively. Digestion was carried out at $37^{\circ} \mathrm{C}$, except for type IV collagen at $25^{\circ} \mathrm{C}$.

\subsection{Effect of Atr-III on $\alpha 2 \beta 1$ Integrin, on its Recombinant $\alpha 2 A$-Domain (r $\alpha 2 A$-Domain) and on Recombinant von Willebrand Factor A1-domain (rWF-A1 Domain)}

The recombinant ectodomain of integrin $\alpha 2 \beta 1$ [46] and its $\mathrm{r} \alpha 2 \mathrm{~A}$-domain were incubated with Atr-III $(10 \mu \mathrm{g})$ in $50 \mathrm{mM} \mathrm{PBS}, \mathrm{pH} 7.4$ at $37^{\circ} \mathrm{C}$ for $5,15,30$, and $60 \mathrm{~min}$ in the absence or presence of $10 \mathrm{mM}$ EDTA, the former ones stopped with $10 \mathrm{mM}$ EDTA and analyzed with SDS-PAGE (7-15\% 
gradient gel). Controls of Atr-III and the undigested integrin or $\mathrm{r} \alpha 2 \mathrm{~A}$-domain alone were included. The rvWF-A1-domain $(5 \mu \mathrm{g})$ was digested with Atr-III $(0.5 \mu \mathrm{g})$ or incubated alone according to [14].

\subsection{Synthesis and Sequencing of cDNA}

The cDNA was obtained from fresh venom of an adult male B. atrox specimen as described [47]. The gene of Atr-III was amplified with the kit Master Mix Platinum ${ }^{\circledR}$ Taq DNA Polymerase (Invitrogen, Carlsbad, CA, USA) according to the manufacturer's instructions. The external primers MpIIIF: 5'gaactcagattggcttgaagga3' and MpIIIR: 5' ggaagtagctacatcttggaaagcc3'(kindly provided by Prof. J. Mendoza, Facultad de Ciencias Biologicas, UNMSM) were designed on the basis of the highly conserved cDNA sequences encoding P-III SVMPs from Bothrops species, bothropasin (B. jararaca, AF056025.2), B. neuwiedi MP-III3 (HM443634.1), jararhagin (B. jararaca, X68251.1), berythractivase (B. erythromelas, AF450503.1), B. jararacussu (RGD-P-III MP DQ408681.1), and B. insularis MP (AF490534.1). Sequencing of the amplification products was performed on an ABI $3730 \mathrm{XL}$ automated sequencer (Macrogen, Inc, South Korea) using the internal primers MpIIIFi: 5' attgttgaggattatagcccaat $3^{\prime}$ and MpIIIRi5' tgcttatcgtgggagccataatt $3^{\prime}$. The obtained protein sequences were compared with sequences deposited in GenBank and SwissProt.

\subsection{Multiple Alignment and Phylogenetic Tree Construction}

Sequence alignments were performed using CLUSTALW multi-sequence alignment program from Bioedit [48]. To examine the evolutionary relationship among SVMPs, a phylogenetic tree was built using the MEGA program v. 6.0 [49] according to the neighbor-joining method. The phylogenetic distance was calculated by the method of Kimura using two parameters and performing 1000 replicates (bootstraps).

\subsection{Modeling of Atr-III Three-dimensional Structure}

A three-dimensional model of Atr-III was predicted using comparative homology modeling [50] based on appropriate homologue templates found with a BLAST search: B. jararaca (PDB code 3DSL|chain B), C. atrox (PDB code 2DWO|chainA) and A. acutus (PDB code 3HDB|chainA) showing $97 \%, 86 \%$, and $84 \%$ identity, respectively, and $99 \%$ query coverage with each one. Starting from these selected templates, 10 models were calculated by the program, Modeller 9.2. RMS deviations VMD v 1.9.2. Stereochemistry of the predicted model was checked by PROCHECK [51]. Metal-binding sites were analyzed by IONCOM server (http://zhanglab.ccmb.med.umich.edu/IonCom/). PyMOL, v.2002 (http://www.pymol.org) was used to illustrate the structure models.

\subsection{Platelet Aggregation Assay}

Human blood from healthy volunteers was collected in acid-citrate-dextrose (ACD: $78 \mathrm{mM}$ citric acid; $117 \mathrm{mM}$ sodium citrate; $282 \mathrm{mM}$ dextrose) [6:1, $(v / v)]$ centrifuged at $200 \times g$ for $15 \mathrm{~min}$ to obtain platelet-rich-plasma (PRP). Washed platelets were isolated as described [14]. Washed platelets were re-suspended in Tyrode's solution, $\mathrm{pH}$ 7.4, containing $2 \mathrm{mM} \mathrm{CaCl} 2$ and $1 \mathrm{mM} \mathrm{MgCl}_{2}$ in absence of prostaglandin E1 (PGE1). Platelet density was adjusted to $2.5 \times 10^{5}$ platelets $/ \mu \mathrm{L}$. Platelet aggregation was carried out in an eight channel platelet aggregometer (AggRam Helena Laboratories, Beaumont, TX, USA) with stirring $(600 \mathrm{rpm})$ at $37^{\circ} \mathrm{C}$. To examine the effect of Atr-III on platelets, washed platelets $(225 \mu \mathrm{L})$ were pre-incubated with several concentrations of Atr-III ( 2 to $32 \mu \mathrm{g} / \mathrm{mL})$ in Tyrode's solution $\mathrm{pH} 7.4$, for $3 \mathrm{~min}$. Platelets were stimulated by addition of different agonists: $6 \mu \mathrm{g} / \mathrm{mL}$ of convulxin (CVX) isolated from Crotalus durissus terrificus snake venom, $10 \mu \mathrm{g} / \mathrm{mL}$ of collagen-I, $7 \mu \mathrm{g} / \mathrm{mL}$ of vWF plus $0.5 \mathrm{mg} / \mathrm{mL}$ of ristocetin. Light transmittance was recorded and the inhibition of platelet aggregation was measured at the maximum aggregation response. 


\subsection{Western Blot Assays}

The possible metalloproteinase degradation of GPIb $\alpha$ and shedding of GPVI from the surface of washed platelets by Atr-III, was analyzed by immunoblotting assay using specific antibodies. To test GPIb $\alpha$ degradation, washed platelets $\left(5 \times 10^{8}\right.$ cells $\left./ \mathrm{mL}\right)$ were incubated with Atr-III $(10 \mu \mathrm{g})$ for $5,15,30$, or $60 \mathrm{~min}$ at $37^{\circ} \mathrm{C}$. The reaction was stopped by addition of SDS sample loading buffer. To assess GPVI shedding, $225 \mu \mathrm{L}$ of washed platelets $\left(5 \times 10^{8}\right.$ cells $\left./ \mathrm{mL}\right)$ were incubated with Atr-III $(10 \mu \mathrm{g})$ at the above conditions. To gain information on the involvement of ADAM10 in GPVI shedding, platelets were incubated with GI254023X $100 \mathrm{nM}$ (3995, Tocris), an specific inhibitor of ADAM10 with or without Atr-III $(10 \mu \mathrm{g})$, and NEM (N-ethylmaleimide) $(10 \mathrm{mM})$ as positive control, for $60 \mathrm{~min}$ at $37^{\circ} \mathrm{C}$. To isolate platelets from incubation medium supernatants, platelets were pelleted by centrifugation at $15,000 \times g$ for $2 \mathrm{~min}$. The supernatant fraction was isolated from pellet and both were mixed with SDS sample loading buffer. All aliquots were separated by SDS-PAGE, transferred to a nitrocellulose membrane and probed with anti-human GPVI polyclonal antibody (AF3627, R\&D Systems), anti-human CD42b/GPIb $\alpha$ polyclonal antibody (AF4067, R\&D Systems), or anti- $\beta$-actin (IM-0075, Imuny) and a secondary alkaline-phosphatase conjugated antibody (Sigma-Aldrich).

\subsection{Platelet Adhesion Assays Using xCELLigence Technology}

The effect of Atr-III on platelets adhesion was quantified by the label-free, impedance-based real-time technology (xCelligence System). To this end, an E-plate was coated with $5 \mu \mathrm{g} / \mathrm{mL}$ of collagen I at $4{ }^{\circ} \mathrm{C}$ overnight. Non-specific binding was blocked with heat-inactivated BSA at a concentration of $1 \%$. The platelets were seeded at a density of $50,000 / \mu \mathrm{L}$, and treated with Atr-III $(32 \mu \mathrm{g} / \mathrm{mL})$ either simultaneously (time 0) or $2 \mathrm{~h}$ later. PBS, instead of Atr-III, was added to the control well. The impedance change depends on the number of attached platelets and their morphometric changes.

Supplementary Materials: The following supplementary information are available online, Figure S1: Purification of Atroxlysin-III from B. atrox venom (1st and 2nd step), Figure S2: The nucleotide and deduced amino acid sequence of Atr-III precursor from B. atrox venom, Figure S3: Effect of Atr-III on platelet aggregation stimulated with convulxin (CVX), collagen or von Willebrand factor plus ristocetin

Author Contributions: Conceptualization, L.S.O. and E.F.S.; methodology, L.S.O., M.I.E.-C., V.G.A., D.E.V.-R., A.Y., A.M.L. and A.C.; writing-original draft preparation, E.F.S. and L.S.O.; writing-review and editing, E.F.S. and J.A.E.; project administration, E.F.S., L.S.O. and J.A.E.; funding acquisition, E.F.S., J.A.E.

Funding: This research was funded by Fundação de Amparo a Pesquisa do Estado de Minas Gerais (FAPEMIG: AUC-00022-16, CBB-APQ-01858-15, BIP-00115-18), Conselho Nacional de Desenvolvimento Científico e Tecnológico (CNPq: 421817/2016-0) and from Deutsche Forschungsgemeinschaft (DFG-grant: Eb177/13-1).

Acknowledgments: We thank Dario Souza and Silea Gontijo for their technical assistance on in vivo and chromatographic assays.

Conflicts of Interest: The authors declare no conflict of interest. The funders had no role in the design of the study; in the collection, analyses, or interpretation of data; in the writing of the manuscript, or in the decision to publish the results.

\section{References}

1. Casewell, N.R.; Wüster, W.; Vonk, F.J.; Harrison, R.A.; Fry, B.G. Complex cocktails: The evolutionary novelty of venoms. Trends Ecol. Evol. 2013, 28, 219-229. [CrossRef] [PubMed]

2. Fry, B.G.; Vidal, N.; Norman, J.A.; Vonk, F.J.; Scheib, H.; Ramjan, S.F.; Kuruppu, S.; Fung, K.; Hedges, S.B.; Richardson, M.K. Early evolution of the venom system in lizards and snakes. Nature 2006, 439, 584-588. [CrossRef]

3. Calvete, J.J. Venomics: Integrative venom proteomics and beyond. Biochem. J. 2017, 474, 611-634. [CrossRef] [PubMed]

4. Lu, Q.; Clemetson, J.M.; Clemetson, K.J. Snake venoms and hemostasis. J. Thromb. Haemost. 2005, 3, 1791-1799. [CrossRef] [PubMed]

5. Escoubas, P.; King, G.F. Venomics as a drug discovery platform. Expert Rev. Proteom. 2009, 6, $221-224$. [CrossRef] [PubMed] 
6. Marsh, N. Practical applications of snake venom toxins in hemostasis. Toxicon 2005, 45, 1171-1181. [CrossRef] [PubMed]

7. Markland, F.S.; Swenson, S.D. Application of snake toxins in biomedicine. In Venom Genomics and Proteomics, Toxinology; Gopalakrishnakone, P., Calvete, J.J., Eds.; Springer: Dordrecht, Germany, 2016; pp. $393-423$.

8. Calvete, J.J.; Borges, A.; Segura, A.; Flores-Dias, M.; Alape-Giron, A.; Gutierrez, J.M.; Diez, N.; De Souza, L.; Kiriokos, D.; Sanchez, E.; et al. Snake venomics and antivenomics of Bothrops colombiensis, a medically important pitviper of the Bothrops atrox-asper complex endemic to Venezuela: Contributing to its taxonomy and snake bite management. J. Proteom. 2009, 72, 227-240. [CrossRef]

9. Kohlhoff, M.; Borges, M.H.; Yarleque, A.; Cabezas, C.; Richardson, M.; Sanchez, E.F. Exploring the proteomes of the venoms of the Peruvian pit vipers Bothrops atrox, B. barnetti and B. pictus. J. Proteom. 2012, 75, 2181-2195. [CrossRef]

10. Takeda, S.; Takeya, H.; Iwanaga, S. Snake venom metalloproteinases: Structure, function and relevance to the mammalian ADAM/ADAMTS family proteins. Biochim. Biophys. Acta 2012, 1824, 164-176. [CrossRef]

11. Fox, J.W.; Serrano, S.M. Insights into speculations about sanke venom metalloproteinase (SVMP) synthesis, folding and disulfide bond formation and their contribution to venom complexity. FEBS J. 2008, 275, 3016-3030. [CrossRef]

12. Takeda, S. ADAM and ADAMTS family proteins and snake venom metalloproteinases: A structural overview. Toxins 2016, 8, 155. [CrossRef] [PubMed]

13. Sanchez, E.F.; Schneider, F.S.; Yarleque, A.; Borges, M.; Richardson, M.; Figueiredo, S.G.; Evangelista, K.; Eble, J.A. The novel metalloproteinase atroxlysin-I from Peruvian Bothrops atrox (Jergón) snake venom acts both on ECM and platelets. Arch. Biochem. Biophys. 2010, 496, 9-20. [CrossRef] [PubMed]

14. Sanchez, E.F.; Richardson, M.; Gremski, L.H.; Veiga, S.S.; Yarleque, A.; Niland, S.; Lima, A.M.; Estevao-Costa, M.I.; Eble, J.A. A novel fibrinolytic metalloproteinase, barnettlysin-I from Bothrops barnetti (barnett's pitviper) snake venom with anti-platelet properties. Biochim. Biophys. Acta. 2016, 1860, 542-556. [CrossRef] [PubMed]

15. You, W.-K.; Jang, Y.-J.; Chung, K.-H. Functional roles of two distinct domains of halysase, a snake venom metalloprotease, to inhibit human platelet aggregation. Biochem. Biophys. Res. Comm. 2006, 339, 964-970. [CrossRef] [PubMed]

16. Gibeler, N.; Zigrino, P. A disintegrin and metalloprotease (ADAM): Historical overview of their functions. Toxins 2016, 8, 122. [CrossRef] [PubMed]

17. Lu, X.; Lu, D.; Scully, M.F.; Kakkar, V.V. Snake venom metalloproteinase containing a disintegrin-like domain, its structure-activity relationships at interacting with integrins. Curr. Med. Chem. Cardiovasc. Hematol. Agents 2005, 3, 249-260. [CrossRef] [PubMed]

18. Tanjoni, I.; Evangelista, K.; Della-Casa, M.S.; Butera, D.; Magalhães, G.S.; Baldo, C.; Clisa, P.B.; Fernandes, I.; Eble, J.; Moura da Silva, A.M. Different regions of the class P-III snake venom metalloproteinase jararhagin are involved in binding to $\alpha 2 \beta 1$ integrin and collagen. Toxicon 2010, 55, 1093-1099. [CrossRef] [PubMed]

19. Gardiner, E.E. Proteolytic processing of platelet receptors. Res. Pract. Thromb. Haemost. 2017, 2, $240-250$. [CrossRef] [PubMed]

20. Gardiner, E.E.; Andrews, R.K. Platelet receptor expression and shedding: Glycoprotein Ib-IX-V and glycoprotein VI. Transfus. Med. Rev. 2014, 28, 56-60. [CrossRef]

21. Ruggeri, C.M. Platelets in atherothrombosis. Nat. Med. 2002, 8, 1227-1234. [CrossRef] [PubMed]

22. Wang, W.-J.; Shih, C.-H.; Huang, T.-F. Primary structure and antiplatelet mechanism of snake venom metalloproteinase, acurhagin, from Agkistrodon acutus venom. Biochimie 2005, 87, 1065-1077. [CrossRef] [PubMed]

23. Kamiguti, A.S. Platelets as targets of snake venom metalloproteinases. Toxicon 2005, 45, 1041-1049. [CrossRef] [PubMed]

24. Wijeyewickrema, L.C.; Gardiner, V.; Moroi, M.; Berndt, M.C.; Andrews, R.K. Snake venom metalloproteinases, crotarhagin and alborhagin, induce ectodomain shedding of platelet collagen receptor, glycoprotein VI. Thromb. Haemost. 2007, 98, 1285-1290. [CrossRef] [PubMed]

25. Nuñez, V.; Cid, P.; Sanz, L.; La Torre, P.D.; Angulo, Y.; Lomonte, B.; Gutierrez, J.M.; Calvete, J.J. Snake venomics and antivenomics of Bothrops atrox venoms from Colombia and the Amazon regions of Brazil, Perú and Ecuador suggest the occurrence of geographic variation of venom phenotype by a trend towards paedomorphism. J. Proteom. 2009, 73, 57-78. [CrossRef] 
26. Calvete, J.J.; Sanz, L.; Perez, A.; Borges, A.; Vargas, A.M.; Lomonte, B.; Angulo, Y.; Gutierrez, J.M.; Chalkidis, H.M.; Mourão, R.H.V.; et al. Snake population venomics and antivenomics of Bothrops atrox: Paedomorphism along its transamazonian dispersal and implications of geographic venom variability on snakebite management. J. Proteom. 2011, 74, 510-527. [CrossRef] [PubMed]

27. Warrell, D.A. Snakebites in Central and South America: Epidemiology, clinical features and clinical management. In The Venomous Reptiles of the Western Hemisphere; Campbell, J.A., Lamar, W.W., Eds.; Comstock Publishing Associates: London, UK, 2004; pp. 709-762.

28. Zavaleta, A. Mordedura de serpiente (Ofidismo): Un problema de salud en el Perú. Rev. Med. Hered. 2004, 15, 61-63. [CrossRef]

29. Paine, M.J.I.; Desmond, H.P.; Theakston, R.D.G.; Crampton, J.M. Purification, cloning and molecular characterization of a high molecular weight hemorrhagic metalloproteinase, jararhagin from Bothrops jararaca venom. J. Biol. Chem. 1992, 267, 22869-22876.

30. Assakura, M.T.; Silva, C.A.; Mendele, R.; Camargo, A.C.M.; Serrano, S.M.T. Molecular cloning and expression, of structural domains of bothropasin, a P-III metalloproteinase from the venom of Bothrops jararaca. Toxicon 2003, 41, 217-227. [CrossRef]

31. Freitas-de-Sousa, L.A.; Amazonas, D.R.; Souza, L.F.; San'tAnna, S.S.; Nishiyama, M.Y.; Serrano, S.M.T.; Junqueira-de Azevedo, I.L.; Chalkidis, H.M.; Moura-da-Silva, A.M. Comparisons of venoms from wild and long-term captive Bothrops atrox snakes and characterization of batroxrhagin, the predominant class P-III metalloproteinase from the venom of this species. Biochimie 2015, 118, 60-70. [CrossRef]

32. Junqueira-de-Azevedo, I.L.; Ho, P.L. A survey of gene expression and diversity in the venom glands of the pitviper snake Bothrops insularis throught the generation of expressed sequence tags (ESTs). Gene 2002, 299, 279-291. [CrossRef]

33. Sanchez, E.F.; Gabriel, L.M.; Gontijo, S.; Gremski, L.H.; Veiga, S.S.; Evangelista, K.; Eble, J.A.; Richardson, M. Structural and functional characterization of a P-III metalloproteinase, leucurolysin-B, from Bothrops leucurus venom. Arch. Biochem. Biophys. 2007, 468, 193-204. [CrossRef] [PubMed]

34. Igarashi, T.; Araki, S.; Mori, H.; Takeda, S. Crystal structures of catrocolastatin/VAP2B reveal a dynamic, modular architecture of ADAM/adamalysin/reprolysin family proteins. FEBS Lett. 2007, 581, 2416-2422. [CrossRef] [PubMed]

35. Wallnoefer, H.C.; Lingott, T.; Gutierrez, J.M.; Merfort, I.; Liedl, K.R. Backbone flexibility controls the activity and specificity of a protein-protein interface: Specificity in snake venom metalloproteases. J. Am. Chem. Soc. 2010, 132, 10330-10337. [CrossRef] [PubMed]

36. Wang, W.-J.; Huang, T.-F. Purification and characterization of a novel metalloproteinase, acurhagin, from Agkistrodon acutus venom. Thromb. Haemost. 2002, 87, 641-650. [CrossRef] [PubMed]

37. Serrano, S.M.T.; Wang, D.; Shannon, J.D.; Pinto, A.F.M.; Polanowska-Grabowska, R.K. Interaction of the cysteine-rich domain of snake venom metalloproteinases with the A1 domain of von Willebrand factor promotes site-specific proteolysis of von Willebrand factor and inhibition of von Willebrand factor-mediated platelet aggregation. FEBS J. 2007, 274, 3611-3621. [CrossRef]

38. Herrera, C.; Voisin, M.B.; Escalante, T.; Rucavado, A.; Nourshargh, S.; Gutierrez, J.M. Effects of PI and PIII snake venom haemorrhagic metalloproteinases on the microvasculature: A confocal microscopy study on the mouse cremaster muscle. PLoS ONE 2016, 11, e0168643. [CrossRef] [PubMed]

39. Bernardoni, J.L.; Sousa, L.F.; Wermelinger, L.S.; Lopes, A.S.; Prezoto, B.C.; Serrano, S.M.T.; Zingali, R.B.; Moura-da-Silva, A.M. Functional variability of snake venom metalloproteinases: Adaptive advantages in targeting different prey and implications for human envenomation. PLoS ONE 2014, 9, e109651. [CrossRef]

40. Wang, W.-J. Purification and functional characterization of AAVI, a novel P-III metalloproteinase, from Formosan Agkistrodon acutus venom. Biochimie 2007, 89, 105-115. [CrossRef]

41. De Meyer, S.F.; Vanhoorelbeke, K.; Broos, K.; Salles, I.I.; Deckmyn, H. Antiplatelet drugs. Br. J. Haematol. 2008, 142, 515-528. [CrossRef]

42. Montague, S.J.; Andrews, R.K.; Gardiner, E.E. Mechanisms of receptor shedding in platelets. Blood 2018, 132, 2535-2545. [CrossRef]

43. Oliveira, A.K.; Leme, A.F.P.; Asega, A.F.; Camargo, A.C.M.; Fox, J.W.; Serrano, M.T.S. New insights into the structural elements involved in the skin haemorrhage induced by snake venom metalloproteinases. Thromb. Haemost. 2010, 104, 485-497. [CrossRef] [PubMed] 
44. Sanchez, E.F.; Santos, C.I.; Magalhaes, A.; Diniz, C.R.; Figueiredo, S.; Gilroy, J.; Richardson, M. Isolation of a proteinase with plasminogen-activating activity from Lachesis muta muta (bushmaster) snake venom. Arch. Biochem. Biophys. 2000, 378, 131-141. [CrossRef] [PubMed]

45. Miles, E.W. Modification of histidyl residues in proteins by diethylpyrocarbonate. Methods Enzymol. 1977, 47, 431-442. [CrossRef] [PubMed]

46. Eble, J.A.; Beermann, B.; Hinz, H.-J. $\alpha 2 \beta 1$ integrin is not recognized by rhodocythin but is the specific high affinity target of rodochetin, an RGD-independent disintegrin and potent inhibitor of cell adhesion to collagen. J. Biol. Chem. 2001, 216, 12274-122784. [CrossRef] [PubMed]

47. Vivas-Ruiz, D.E.; Sandoval, G.A.; Mendoza, J.; Inga, R.R.; Gontijo, S.; Richardon, M.; Eble, J.A.; Yarleque, A.; Sanchez, E.F. Coagulant thrombin-like enzyme (barnettobin) from Bothrops barnetti venom: Molecular sequence analysis of its cDNA and biochemical properties. Biochimie 2013, 95, 1476-1486. [CrossRef] [PubMed]

48. Hall, T.A. BioEdit: A user-friendly biological sequence alignment editor and analysis program for Windows 95/98/NT. Nucl. Acids Symp. Ser. 1999, 41, 95-98.

49. Tamura, K.; Stecher, G.; Peterson, D.; Filipski, A.; Kumar, S. MEGA6: Molecular Evolutionay Genetics Analysis Version 6.0. Mol. Biol. Evol. 2013, 30, 2725-2729. [CrossRef]

50. Sali, A.; Blundell, T.L. Comparative protein modelling by satisfaction of spatial restraints. J. Mol. Biol. 1997, 234, 779-815. [CrossRef]

51. Laskowski, R.A.; Macarthur, M.W.; Moss, D.S.; Thorton, J.M. PROCHECK: A program to check the stereochemical quality of protein structures. J. Appl. Cryst. 1993, 6, 283-291. [CrossRef]

Sample Availability: Samples of the compounds are not available from the authors.

(C) 2019 by the authors. Licensee MDPI, Basel, Switzerland. This article is an open access article distributed under the terms and conditions of the Creative Commons Attribution (CC BY) license (http://creativecommons.org/licenses/by/4.0/). 